Published in final edited form as:

Pflugers Arch. 2014 June ; 466(6): 1037-1053. doi:10.1007/s00424-014-1480-8.

\title{
Heart failure with preserved ejection fraction
}

\author{
James D. Gladden, \\ Division of Cardiovascular Diseases, Department of Medicine, Mayo Clinic, Guggenheim 9, 200 \\ First Street, Southwest Rochester, MN 55905, USA \\ Wolfgang A. Linke, and \\ Department of Cardiovascular Physiology, Ruhr University Bochum, Bochum, Germany

\section{Margaret M. Redfield} \\ Division of Cardiovascular Diseases, Department of Medicine, Mayo Clinic, Guggenheim 9, 200 \\ First Street, Southwest Rochester, MN 55905, USA, redfield.margaret@mayo.edu
}

\begin{abstract}
As part of this series devoted to heart failure (HF), we review the epidemiology, diagnosis, pathophysiology, and treatment of HF with preserved ejection fraction (HFpEF). Gaps in knowledge and needed future research are discussed.
\end{abstract}

\section{Keywords}

Heart failure; Diastole

\section{Epidemiology and diagnosis}

Community-based studies indicate that approximately $50 \%$ of patients with a clinical diagnosis of $\mathrm{HF}$ have a normal or near normal ejection fraction (EF) [6, 27, 94], but the portion of $\mathrm{HF}$ associated with preserved $\mathrm{EF}(\mathrm{HFpEF})$ varies according to study setting and methodologies [93]. The EF value used to define "preserved" EF has ranged from 40 to 55 $\%$, but current guidelines recommend $\mathrm{EF}>50 \%$ with normal $\mathrm{LV}$ size as criteria for $\mathrm{HFpEF}$ $[85,131]$.

In the community, the mortality and hospitalization rates are similar for the two types of HF, but clinical trials enrolling patients with both types of HF generally show lower event rates in HFpEF than HF with reduced EF (HFrEF) [28]. Survival has improved over time in HFrEF, but not in HFpEF [94]. Importantly, the portion of patients with HF who have preserved EF appears to be increasing over time [94, 120].

HFpEF is a clinical syndrome rather than a discrete disease and thus cannot be easily ascribed to a single etiology. In most cases, HFpEF occurs in older individuals and is more common in women [93]. HFpEF is nearly always associated with multiple cardiovascular

(C) Springer-Verlag Berlin Heidelberg 2014

Correspondence to: Margaret M. Redfield. 
and non-cardiovascular comorbidities including hypertension, coronary artery disease (CAD), corrected valvular disease, diabetes mellitus, obesity, dyslipidemia, disordered sleep breathing, lung disease, anemia, and renal disease. Some studies suggest that HFpEF patients have a higher comorbidity burden than patients with $\mathrm{HFrEF}$ [5, 35], but a community HF surveillance study enrolling older HF patients did not find differences in the comorbidity burden of the two types of HF [27, 28]. Nonetheless, non-cardiac deaths are more common in HFpEF than HFrEF [21, 51, 120].

Patients with discrete cardiac conditions known to cause HF in the setting of preserved EF (untreated primary valve disease, pericardial disease, congenital heart disease, high-output $\mathrm{HF}$, and hypertrophic or infiltrative cardiomyopathies) are unique entities with specific pathophysiology and treatment and are not considered as HFpEF, although persistent diastolic dysfunction and $\mathrm{HF}$ after correction of severe aortic stenosis may represent a subset of patients with HFpEF. As signs and symptoms of HF are nonspecific, a diagnosis of HFpEF is strengthened by concurrent evidence of diastolic dysfunction, structural abnormalities such as left ventricular hypertrophy or left atrial enlargement, and serological markers such as brain natriuretic peptide (BNP) and NT-proBNP, but none of these are necessary or sufficient to make the diagnosis [12]. While BNP assays can be helpful in establishing the diagnosis and prognosis of HFpEF, the levels are lower in HFpEF than $\mathrm{HFrEF}$ due to obesity, transient elevation of filling pressures in early $\mathrm{HFpEF}$, and lower wall stress (the stimulus to BNP production by the cardiomyocyte) due to the concentric remodeling characteristic of HFpEF [61]. Diastolic dysfunction is typically documented by resting Doppler echocardiographic measures (Fig. 1). Like any diagnostic test, these Doppler echocardiographic measures have imperfect sensitivity and specificity for hemodynamic derangements, but are useful for both epidemiologic studies and clinical management as long as their limitations are recognized and direct invasive assessment is utilized when the clinical suspicion for HFpEF is high, but noninvasive measures are negative or inconclusive. Much emphasis has been placed on the $E / e^{\prime}$ ratio as a marker of elevated filling pressures. However, the predictive characteristics of $E / e^{\prime}$ for elevated pulmonary capillary wedge pressure were only "good" with an area under the receiver operating characteristics curve of approximately 0.80 [92]. An $E / e^{\prime}$ of $>15$ is fairly specific, but quite insensitive for elevated filling pressures. The more parameters that are abnormal, the more confidence can be placed in the diagnosis of elevated filling pressures, and a comprehensive evaluation is critical and should include measurement of the pulmonary artery systolic pressure (PASP), which is usually at least mildly elevated in HFpEF patients [80]. Importantly, in HFpEF patients with purely exertional symptoms, resting filling pressures may be normal, but with exertion, filling pressures may rise rapidly [17].

\section{Pathophysiology of HFpEF}

Here, we will review insights into HFpEF pathophysiology derived from clinical studies utilizing imaging and physiologic testing, the few studies which have examined myocardial tissue from HFpEF patients and proposed unifying paradigms for the genesis of HFpEF. Emphasis is placed on human studies. 


\section{Cardiovascular structure and function in HFpEF: integrative pathophysiology}

The integrative physiology of human HFpEF has been extensively studied; critical features are outlined below.

\section{LV hypertrophy}

Imaging studies indicate that, on average, patients with HFpEF have higher LV mass than healthy controls or patients with hypertension without HF due to concentric remodeling [81, 88]. However, nearly $40 \%$ of patients do not meet echocardiographic criteria for hypertrophy [136], and the severity of hypertrophy does not distinguish between hypertensive patients with and without HF [80]. A longitudinal community-based study demonstrated that over time, LV systolic and diastolic stiffness increased in older persons despite the fact that use of anti-hypertensive therapies increased and LV mass decreased over time, questioning the central role of progressive hypertrophic remodeling in the genesis of LV dysfunction in HFpEF [19]. Lastly, diastolic dysfunction is common in patients with hypertension and unrelated to the presence or severity of hypertrophy [117].

\section{LV diastolic function}

Whether assessed invasively $[14,135]$ or noninvasively [81, 88], at rest, patients with HFpEF have more impaired LV relaxation and diastolic stiffness compared to healthy or hypertensive controls without HF. Importantly, diastolic dysfunction and elevation of filling pressure may be absent at rest in patients with predominantly exertional symptoms (impaired diastolic reserve) $[17,20]$. While diastolic dysfunction is thought to play a key role in the genesis of symptoms in HFpEF, noninvasive evidence of diastolic dysfunction is very common in elderly patients without HFpEF [105]. Thus, resting diastolic dysfunction appears necessary, but not necessarily sufficient to produce HFpEF.

Slow relaxation-Relaxation is regulated by factors that affect cross-bridge detachment including calcium regulation of the troponin complex, the chemical steps in cross-bridge adenosine triphosphate (ATP) cycling, mechanics of force generation, and length dynamics of individual sarcomeres [119]. Cardiac relaxation depends on both energy-dependent calcium $\left(\mathrm{Ca}^{2+}\right)$ reuptake and elastic recoil determined by the viscoelastic properties of the myocardium. $\mathrm{Ca}^{2+}$ removal is primarily via the sarcoplasmic reticulum $\mathrm{Ca}^{2+}$ ATPase (SERCA2a) and the sarcolemmal sodium-calcium exchanger [71]. The appropriate function of this process requires adequate SERCA2a expression/regulation and cardiomyocyte bioenergetics. Adenoviral transfer of SERCA2a improves LV relaxation rate in rats [107], and decreased SERCA2a activity accelerated heart failure in a mouse model [110]. Phospholamban inhibits SERCA2a function in its unphosphorylated state, and studies have demonstrated a phosphomimetic improved diastolic function in animal models of HF [57, 67]. Natriuretic peptides or nitric oxide increases cGMP and protein kinase G (PKG) and hasten relaxation, likely via effects on calcium sensitivity [97, 130]. As calcium reuptake is highly energy-dependent, relaxation is very sensitive to ischemia or myocardial energetic deficits known to be present in HFpEF [99]. 
The role of impaired relaxation in contributing to elevation in filling pressures at rest or with exercise in HFpEF has been difficult to establish, in part due to the lack of agents which acutely and selectively alter lusitropic function. Impairment in LV relaxation can elevate LV pressures in early diastole, but modeling experiments indicate that impaired LV relaxation does not elevate mean and end-diastolic pressures at normal heart rates. However, in the presence of tachycardia, impairment in LV relaxation can result in elevated mean and enddiastolic LV pressure [50] (Fig. 2). A study of HFpEF patients undergoing exercise with hemodynamic monitoring showed that relaxation improved (decrease in the time constant of isovolumic relaxation, $\tau$ ) by 8-30\% (depending on tau calculation technique) with exercise, but the percent of diastole required for complete relaxation increased due to the tachycardia and loss of diastasis [14]. However, studies using noninvasive estimates of relaxation (time to peak filling or $e^{\prime}$ velocity) during exercise have varied, with some finding no change and others finding worsening of relaxation with exercise in $\mathrm{HFpEF}[69,99]$.

Of note is that a recent study comparing exercise performance in HFpEF with or without treatment with the $\mathrm{I}_{f}$ channel inhibitor ivabradine showed that peak oxygen uptake $\left(\mathrm{VO}_{2}\right)$ increased dramatically after short-term (7 days) therapy with ivabradine [69]. The dramatic improvement in $\mathrm{VO}_{2}$ was associated not only with a reduction in peak heart rate but also with accelerated LV relaxation (increased $e^{\prime}$ velocity) at rest and with exercise and attenuation of exercise-induced increase in filling pressures $\left(E / e^{\prime}\right)$. The improvement in myocardial relaxation may be due to a direct effect of ivabradine on myocardial relaxation or effects on arterial load [106]. These favorable effects may be specific to the disease state as acute administration of ivabradine in normal dogs did not show acute effects on relaxation at rest or with exercise [30].

LV diastolic stiffness-The presence of increased LV diastolic stiffness is implied by elevation of resting $\mathrm{LV}$ filling pressures in the setting of normal or reduced $\mathrm{LV}$ volume in $\mathrm{HFpEF}$, but has also been demonstrated by noninvasive estimates of diastolic stiffness [81] and by invasive pressure volume analysis using single-beat analysis to reconstruct diastolic pressure-volume relationships at rest and with exercise (Fig. 3) [14, 135]. The concept of increased myocardial stiffness solely as a passive, chronic condition resulting from myocardial fibrosis has been abandoned as studies have shown that while fibrosis and enhanced collagen stiffness due to collagen cross-linking are present in HFpEF and associated with increased myocardial or LV diastolic stiffness [9, 65, 123, 125], diastolic myocardial stiffness is increased even in patients without increased fibrosis [9] and acute changes in myocardial diastolic stiffness can occur due to ischemia [108] or, as reviewed below, other factors which affect titin properties.

\section{LV systolic performance}

While EF is maintained in HFpEF, systolic chamber and myocardial function are not normal in HFpEF. LV systolic stiffness (end-systolic elastance, $E_{\mathrm{es}}$ ) is coupled to increases in arterial stiffness (arterial elastance, $E_{\mathrm{a}}$ ) to maintain stroke volume and mechanical efficiency. While $E_{\text {es }}$ is a measure of contractility, it is also affected by chamber remodeling and passive myocardial stiffening, and human and animal studies confirm that $E_{\mathrm{es}}$ can be increased in the setting of impaired myocardial contractility [11, 26, 98]. Both $E_{\mathrm{a}}$ and $E_{\mathrm{es}}$ are 
increased as compared to normal subjects in patients with hypertension without $\mathrm{HF}$ and in HFpEF patients $[15,81,88]$. In hypertensive patients without $\mathrm{HF}$, increases in $E_{\mathrm{es}}$ are associated with increased myocardial contractility, as assessed by stress-corrected endocardial or midwall myofiber shortening and other load-insensitive parameters, while in $\mathrm{HFpEF}$, contractility is reduced, suggesting that in HFpEF, increases in $E_{\mathrm{es}}$ are related to increased passive stiffness [15]. Factors that enhance stiffness in diastole may be magnified in systole, and increases in diastolic stiffness $\left(E_{\mathrm{d}}\right)$ are coupled to increases in $E_{\mathrm{es}}[11,15$, 26]. Reduction in myocardial contractility was associated with mortality [15] in HFpEF, suggesting that processes mediating the subtle impairment in contractility may be important in the pathophysiology of HFpEF. Consistent with this, EF declines (modestly) over time in $\mathrm{HFpEF}$, independent of CAD or myocardial infarction, and the severity of decline is associated with mortality [34]. Importantly, even in the absence of epicardial CAD, HFpEF patients do not increase their EF normally in response to exercise or beta-adrenergic stimulation $[18,91,99,100]$. Impairment in systolic reserve in the setting of normal or reduced LV volume may contribute to inability to increase cardiac output with stress.

\section{Coronary vasculature}

There is some controversy over whether patients who present with HF and normal EF and who are found to have CAD should be considered to have HFpEF.

Epicardial CAD—Observational studies indicate that $50 \%$ of patients with HFpEF carry a clinical diagnosis of CAD [25, 88], but concern over under- and over-diagnosis of CAD in elderly HFpEF patients exists [29]. Dyspnea can be an anginal equivalent, but in the setting of normal EF, but the vast majority of patients with chronic stable CAD do not have HF. Many patients with hypertensive pulmonary edema have CAD, but do not develop reduced EF or wall motion abnormalities during the acute HF event despite marked increases in load [42]. Patients with HFpEF, hypertensive pulmonary edema, and CAD who underwent coronary revascularization frequently had recurrent hypertensive pulmonary edema [70]. In a small study, patients with $\mathrm{HF}, \mathrm{EF}>40 \%$, and prior myocardial infarction had better outcomes if treated with beta-blockers [4], but the effect of anti-anginal therapy and revascularization on the clinical course of patients with $\mathrm{HFpEF}$ is not well defined. In observational studies, HFpEF patients treated with statins have better outcomes [41], and whether this is due to an effect on CAD progression or inflammation is unclear [96].

Coronary microvasculature-Patients with HFpEF may also complain of chest pain in the absence of $\mathrm{CAD}$, and this may be related to elevated filling pressures with reduction in coronary perfusion pressure during diastole, coronary endothelial dysfunction, or microvascular rarefaction [55]. Coronary microvascular rarefaction has been postulated to play a role in limiting systolic and diastolic reserve, predisposing to chronic ischemia and fibrosis and progression to HF, but, to date, has not been investigated in HFpEF patients [55, $116]$.

\section{Peripheral vasculature}

Studies suggest that patients with HFpEF have reduced aortic distensibility [59] and higher total arterial load (arterial elastance, $E_{\mathrm{a}}$ ) than healthy controls [81, 88]. Systemic 
vasorelaxation in response to exercise is attenuated in $\mathrm{HFpEF}$ due to impaired endothelial function $[16,18,37]$. Both decreases in aortic distensibility and flow-mediated vasodilatation correlate with the severity of exercise intolerance in $\mathrm{HFpEF}[18,59]$.

\section{Ventricular vascular coupling}

The increases in $E_{\mathrm{a}}$ and $E_{\mathrm{es}}$ in HFpEF produce heightened sensitivity to changes in preload and afterload. Increases in load thus produce greater increases in blood pressure, which can accentuate impairment in relaxation and diastolic stiffness and predispose to flash pulmonary edema $[43,115]$. Decreases in load due to overdiuresis or vasodilators result in exaggerated decreases in blood pressure and limit the improvement in stroke volume with afterload reduction, which figures so prominently into therapeutic strategies in $\mathrm{HFrEF}$ (Fig. 4) [112]. This fundamental difference in LV mechanics may contribute to the differences in response to vasodilating neurohumoral antagonists seen in HFpEF and HFrEF [13].

With exertion, ventricular vascular coupling is normally enhanced with marked increases in $E_{\mathrm{es}}$ and much smaller increases in $E_{\mathrm{a}}$ (balance of decreases in resistance and increased contribution of aortic stiffness and heart rate during exercise), resulting in a decrease in $E_{\mathrm{a}} / E_{\mathrm{es}}$ and maximizing increases in stroke volume with exertion. In HFpEF, decreases in the $E_{\mathrm{a}} / E_{\text {es }}$ ratio with exercise are markedly blunted, resulting in blunted increases in stroke volume $[1,18]$.

\section{Left atrium}

The left atrium (LA) is enlarged in HFpEF, and the degree of atrial remodeling is a rough index of severity and chronicity of HFpEF [86]. Decreases in LA compliancemay be due to atrial volume overload or an upwards shift of the LA pressure-volume relationship. Atrial physiology is complex as the atrium has booster (atrial contraction), conduit (flow from pulmonary veins to LV during LV diastolic filling), and reservoir (atrial filling during ventricular systole) function [56]. Reduced LA compliance is an important contributor to mean LA pressures, PASP, and right heart load in left heart disease and manifests as large "V waves" in LA or pulmonary capillary wedge pressure wave forms, particularly during exercise and in the absence of significant mitral regurgitation (Fig. 5) [8, 48, 111]. Indeed, such wave forms are a hemodynamic hallmark of HFpEF.

Chronic LA pressure overload and structural remodeling in HFpEF leads to electrical remodeling and predisposes to atrial fibrillation, which occurs in two thirds of HFpEF patients at some point in their natural history [133]. Atrial fibrillation is associated with a more severe clinical and structural phenotype, more impaired exercise capacity, and worse outcomes $[132,133]$. Whether atrial fibrillation is simply a marker of more advanced LV dysfunction and HF or contributes to the progression of HFpEF via loss of atrio-ventricular synchrony, inappropriate heart rate regularity or responsiveness or via impaired LA compliance with increases in pulmonary venous and right ventricle (RV) load is unclear. Studies of rate vs. rhythm control in atrial fibrillation have not included patients with HFpEF. 


\section{Pulmonary vasculature and RV}

The chronic pulmonary venous hypertension in HFpEF leads to increases in PASP mediated both by the passive pulmonary venous hypertension and by increases in pulmonary arterial resistance, leading to "out-of-proportion" pulmonary hypertension, increases in RV load, and, ultimately, RV dysfunction [80, 122]. The degree of pulmonary hypertension is a sensitive measure of disease severity as it is potently associated with outcomes in HFpEF [80].

\section{Ventricular interdependence}

The pericardium and external forces contribute one third of resting LVend-diastolic pressure [31] and may play a greater role with stress. Enhanced ventricular interdependence has been postulated to play a prominent role in the pathophysiology of HFpEF [66]. Marked atrial or RV enlargement in HFpEF may exaggerate ventricular interdependence.

\section{Chronotropic incompetence}

A majority (50-75\%, depending on rigor of criteria for chronotropic incompetence) of patients with HFpEF display chronotropic incompetence independently of negative chronotropic agents $[16,18,23,104]$. Impairment in chronotropic reserve may reflect $\beta$ adrenergic receptor desensitization [16] or global autonomic dysfunction. While adequate chronotropic reserve is a key contributor to adequate cardiovascular reserve [22], it remains unclear whether increasing rate responsiveness would enhance exercise tolerance in HFpEF. It is notable that while rate-adaptive pacing is uniformly used in patients receiving pacing for bradycardia, its value in improving exercise tolerance or symptoms is not well established [82]. Indeed, paradoxically, a negative chronotropic agent, the $\mathrm{I}_{f}$ channel antagonist ivabradine improved maximal exercise capacity dramatically in HFpEF (above) [106].

\section{Reserve dysfunction}

A cardinal feature of HF is exertional intolerance, and while episodes of acute decompensated $\mathrm{HF}$ and advanced symptoms are common in $\mathrm{HFpEF}$, a significant portion of patients have exertional dyspnea as their predominant symptom, and HFpEF patients uniformly have reduced submaximal and maximal exercise performance [16-18, 36, 37, 68, 99, 100, 104]. As outlined above, patients with HFpEF display multiple abnormalities in all functions which contribute to exertional capacity with reduced chronotropic, peripheral vasodilatory, LV diastolic, LV systolic, and ventricular-vascular coupling reserve functions. It is logical to assume that reserve dysfunction is the first manifestation of "early HFpEF" [17].

\section{Summary of integrative HFpEF pathophysiology}

The studies reviewed above indicate the multiple perturbations in cardiovascular function apparent in patients with HFpEF, which are summarized in Fig. 6, and underscore the challenges for finding effective therapies. 


\section{Myocardial structure and function in human HFpEF: cardiomyocyte biology}

The underlying myocardial alterations in human HFpEF are incompletely defined as endomyocardial biopsy, and surgical specimens commonly available in HFrEF are rarely available in HFpEF. A small number of studies obtained endomyocardial biopsies in highly selected, younger HFpEF patients and variable comparator groups; their findings are reviewed below.

\section{Cardiomyocyte stiffness}

Consistent with the increased LV chamber diastolic stiffness in HFpEF, increased passive cardiomyocyte stiffness is present in HFpEF as compared to controls [9]. As compared to patients with HFrEF, passive cardiomyocyte stiffness was greater in HFpEF [123] and greater in diabetic than nondiabetic HFpEF patients [125]. Importantly, cardiomyocyte stiffness was similarly increased in HFpEF patients with normal collagen volume fraction [9].

\section{Myocardial fibrosis}

Fibrosis is a nearly invariant feature of hypertrophic remodeling in humans and animal models and may be due to inflammation, ischemia, and neurohumoral and cytokine activation in disease states associated with increased load leading to increased collagen deposition and reduced fibrinolysis [24]. The increases in collagen volume fraction and collagen cross-linking reported in several studies indicate that, on average, myocardial fibrosis is present in HFpEF and contributes to diastolic dysfunction $[9,10,65,123-125$, 129].

In RV endomyocardial biopsy specimens from controls and younger HFpEF patients (median age, 60 years) with hypertrophy and diastolic dysfunction, collagen I and III protein and gene expression, collagen I/III ratio, and tissue inhibitor of metalloproteinase (TIMP-1) expression were increased while cardiac matrix metalloproteinase (MMP-1) expression was decreased, consistent with both increased deposition and inhibited degradation of collagen in HFpEF [129]. While patients had normal plasma c-reactive protein (CRP) levels, there was increased expression of the vascular cell adhesion molecule VCAM-1, which initiates transendothelial migration of inflammatory cells to the myocardium, and TGF- $\beta$-secreting inflammatory cell infiltration was present. Harvested cardiac fibroblasts showed myofibroblast transdifferentiation and increased collagen production and TIMP-1 expression in response to incubation with TGF- $\beta$. This study provided strong evidence that cardiac inflammation may be an initiator or propagator of cardiac fibrosis in HFpEF. The genesis of the inflammatory response remains to be defined, but chronic hemodynamic stress, neurohumoral activation, and/or comorbidities may all play a role. Very recently, studies in murine myocardial infarction further implicate inflammation in the pathophysiology of HF, showing that activation of mononuclear phagocytes is central to the progression of cardiac remodeling in $\mathrm{HF}$ and that heightened antigen processing in the spleen plays a critical role in this process. Splenocytes (presumably splenic monocytes and dendritic cells) promote immune-mediated injurious responses in the failing heart. Activated splenocytes from HF mice promote cardiac injury when infused into non-HF mice [60]. 
Chronic ischemia with cell death and replacement fibrosis may result from epicardial CAD, which is common in HFpEF [25, 88]. Furthermore, it has been postulated that coronary microvascular density may be decreased in HFpEF due to destruction of microvessels or inadequate angiogenesis and contribute to chronic ischemia and the progression to HF [55, $116]$.

\section{Nitric oxide signaling}

In endomyocardial biopsies from patients with $\mathrm{HFpEF}, \mathrm{HFrEF}$, or aortic stenosis, impairment in coronary microvascular endothelial cell-cardiomyocyte nitric oxide signaling was evident in HFpEF as compared to aortic stenosis or HFrEF patients, with decreases in cGMP concentrations, lower PKG activity, and increased markers of nitrosative/oxidative stress (increased myocardial nitrotyrosine levels) in HFpEF patients [124]. The reduction in PKG activity was associated with increases in passive cardiomyocyte stiffness, and this and previous studies show that cardiomyocyte stiffness is acutely reduced with the addition of PKG or protein kinase A (PKA) in vitro, findings related to the phosphorylation of phosphosensitive sites on titin which modulate titin and cardiomyocyte passive stiffness (see below). The reduction of cGMP and PKG activity in HFpEF did not appear to be due to increases in cGMP-degrading phosphodiesterases (PDE) or a reduced expression of the NO receptorsoluble guanylyl cyclase (sGC). Rather, lower levels of the cGMP-generating natriuretic peptides were demonstrated and reduced NO bioavailability or sGC activity due to oxidative stress was suggested by the higher myocardial nitrotyrosine levels. While this study did not include analysis of normal human myocardium, these findings indicate that the cGMP signaling in HFpEF is strikingly different from that of other forms of hypertrophic remodeling.

\section{Titin structure and function}

A well-studied mechanism in HFpEF is the contribution of the large sarcomeric protein titin to passive cardiomyocyte, myocardial, and LV stiffness. Titin is a filamentous protein that spans from the Z-disc to the M-band of the sarcomere (Fig. 7) and functions as a physiological spring when the cardiomyocyte is stretched and as a regulatory node that integrates cardiomyocyte signaling pathways $[73,74]$. In the heart, titin exists in two isoforms due to alternative splicing: the shorter, stiffer N2B isoform and the more compliant N2BA isoform [39]. The ratio of these two isoforms varies by species, during fetal development, and with altered hormonal status [73]. Mechanisms regulating alternative splicing are incompletely understood, but activation of the PI3K/AKT/mTOR pathway by hormonal factors has been shown to promote the expression of the N2B isoform [75, 76]. As recently reviewed [83], emerging data implicate an RNA-binding motif protein (RBM20) in the regulation of alternative splicing of titin and other myocardial proteins [47]. Mutations in titin [52] and in RBM20 increasing the N2BA:N2B ratio can result in dilated cardiomyopathy, but understanding the effect of cardiovascular disease on the regulation of RBM20 will be important to understand the mechanisms mediating, and the therapeutic potential of regulating, splicing in inherited or non-inherited forms of HF.

The ratio of N2BA/N2B expression impacts cardiomyocyte and, along with the extracellular matrix, myocardial stiffness $[84,89,90]$. While one might expect decreases in the 
$\mathrm{N} 2 \mathrm{BA} / \mathrm{N} 2 \mathrm{~B}$ ratio if titin isoform switches were to contribute to myocardial stiffening in $\mathrm{HFpEF}$, endomyocardial biopsies from patients with HFpEF, HFrEF, and aortic stenosis indicate increases rather than decreases in the $\mathrm{N} 2 \mathrm{BA} / \mathrm{N} 2 \mathrm{~B}$ ratio in failing or hypertrophied non-failing myocardium as compared to controls (Fig. 8), which may occur in response to chronic increases in wall stress [10]. Studies in a canine HFrEF model indicate that differential splicing and variable N2BA/N2B ratios may occur in the different cardiac chambers with dramatic reductions in N2BA/N2B ratio in atrial and right ventricular tissue despite minimal changes in the LV in a tachy-paced model of systolic dysfunction [62].

Another titin-related mechanism which impacts cardiomyocyte stiffness is the phosphorylation of a number of sites in the elastic portion of the titin molecule (Fig. 7). Phosphorylation of the cardiac-specific N2-B domain [73] by PKA (activated by $\beta$ adrenergic signaling-derived cAMP), PKG (activated by NO or natriuretic peptide-derived cGMP), ERK2, or $\mathrm{Ca}^{2+} /$ calmodulin-dependent protein kinase II $\delta$ (CaMKIII) decreases titin rigidity and cardiomyocyte passive stiffness [40, 72, 77, 102]. Additional sites phosphorylated by certain kinases have been identified in the disordered PEVK region of titin where PKCa (activated by a-adrenergic activation) phosphorylation increases titin and cardiomyocyte passive stiffness $[54,58]$, whereas CaMKII $\delta$ (activated by calcium) can phosphorylate multiple sites on N2-B and PEVK titin [49, 53] (Fig. 7) which decreases titin and cardiomyocyte stiffness $[49,53]$. Lastly, the cardiac-specific N2-B domain of titin has the potential for the formation of disulfide bonds, and this mechanism could increase titin and cardiomyocyte stiffness in conditions where inflammation and oxidative stress favor disulfide bond formation [45].

In endomyocardial biopsies from patients with $\mathrm{HFpEF}, \mathrm{HFrEF}$, and aortic stenosis, cardiomyocyte passive stiffness was increased in HFpEF and HFrEF, but not aortic stenosis tissue [10]. Incubating cardiomyocytes with PKA markedly reduced but did not normalize cardiomyocyte stiffness in both forms of HF, but more so in HFpEF than HFrEF (Fig. 8) [10]. In a canine HFpEF model, administration of the PDE-5 inhibitor sildenafil (to inhibit cGMP catabolism, increase cGMP, and enhance PKG signaling) in vivo was associated with increased N2B titin phosphorylation, decreased cardiomyocyte stiffness, and enhanced LV chamber compliance [7]. Increased diastolic compliance was seen with sildenafil administration to post-myocardial infarction patients with diastolic dysfunction [3], although sildenafil did not increase exercise capacity in the post-myocardial infarction patients or in patients with HFpEF [104]. However, as noted above, in LV tissue from HFpEF patients, cGMP expression and PKG activity were reduced and exogenous administration of PKG reduced cardiomyocyte stiffness in vitro, but the reduction in PKG activity appeared linked primarily to decreases in NO-sGC activity and potentially decreased natriuretic peptide-pGC signaling rather than to increased PDE-5 [124]. This suggests that alternate therapeutic strategies targeting enhancing cGMP production would better enhance PKG activity, titin phosphorylation, and diastolic function in HFpEF.

\section{Unifying paradigms for HFpEF pathophysiology}

Controversy over the diagnostic criteria, clinical heterogeneity, limited availability of human tissue, and absence of well-accepted animal models have hindered efforts to define a 
unifying paradigm for the pathophysiology of HFpEF. Current and not necessarily mutually exclusive paradigms are reviewed.

\section{Hypertrophic remodeling and RAAS activation}

Studies in experimental models of pressure overload, human valvular disease, and human hypertension have implicated chronic increases in afterload with hypertrophic remodeling as an initially adaptive process that ultimately becomes associated with maladaptive genetic, proteomic, and metabolomic perturbations that manifest with impaired LV diastolic and systolic function [24]. As a history of hypertension is present in most patients with HFpEF, pathologic hypertrophy and RAAS activation has been postulated to be the unifying paradigm in HFpEF [44, 127, 134]. The indisputable fact that blood pressure control (irrespective of the agents used) prevents HF (including HFpEF) lends strong support to this paradigm. However, as noted above, the fact that the severity of hypertrophy per se correlates poorly with HFpEF development or severity and that conventional vasodilating neurohumoral antagonists do not meaningfully modify disease progression once HFpEF [113] is apparent raises the possibility that other factors interact with or are more important than hypertrophic remodeling and RAAS activation in the genesis of HFpEF.

\section{Multi-morbidity}

Some have speculated that HFpEF is merely a culmination of the individual effects of comorbidities on myocardial and vascular function [32, 95, 114]. However, cardiovascular structure and function are more abnormal in HFpEF than individuals without $\mathrm{HF}$ after adjusting for cumulative burden of comorbidities [88], and outcomes are worse in patients with HFpEF as compared to comorbidity-matched patients without HF [28]. The mechanisms distinguishing HFpEF patients from similarly aged patients with similar comorbidity burden remain elusive, but age-comorbidity or comorbidity-comorbidity interactions may be important $[78,79]$.

\section{Coronary microvascular inflammation}

A novel and specific paradigmfor HFpEF (Fig. 9) has recently been proposed based on the elegant series of studies in human HFpEF tissue reviewed above [96]. While not entirely exclusive of the other paradigms, this paradigm provides specific mechanisms and speculates that comorbidities induce a proinflammatory state, with coronary microvascular endothelial cell inflammation and reactive oxygen species (ROS) production. ROS interfere with $\mathrm{NO} / \mathrm{sGC/cGMP}$ signaling through scavenging of $\mathrm{NO}$ and formation of the strong oxidant peroxynitrite. Increased oxidative stress affects sGC by both decreasing its expression levels and impairing NO-induced activation [96]. Thus, ROS production can limit cGMP production and PKG activity. Endothelial cell production of VCAM-1 allows inflammatory cells to migrate to the myocardium where they secrete TGF- $\beta$, driving the activation of resident fibroblasts to myofibroblasts. Inflammation-induced fibrosis, loss of the anti-hypertrophic effects of PKG, and decreases in PKG-mediated titin phosphorylation all lead to myocardial remodeling and diastolic dysfunction. This paradigm is also supported by studies suggesting the activation of inflammatory biomarkers in HFpEF, observational studies showing better outcomes in statin-treated HFpEF patients [41], and promising results from a small study of the interleukin-1 antagonist anakinra in patients with HFpEF and 
elevated CRP levels wherein improvements in CRP and peak exercise capacity were observed [126]. Whether these mechanisms drive HFpEF physiology in all HFpEF patients or only in the younger subjects without CAD included in the myocardial biopsy studies is unclear, but this unifying hypothesis is clearly deserving of further study. Growing comfort with the concept of anti-inflammatory therapy in the prevention of cardiovascular disease [87] may enable therapeutic trials for the prevention or treatment of HFpEF based on this paradigm.

\section{HFpEF treatment}

Treatment of HFpEF is empiric and exclusively based on expert consensus with no specific proven medical therapies [131].

\section{Trials of standard HFrEF therapies in HFpEF}

Randomized clinical trials (RCTs) of angiotensin-converting enzyme inhibitors or angiotensin receptor blockers (ARB) did not meaningfully impact outcomes in HFpEF even when the results were pooled in a meta-analysis [113]. Beta-blockers have not been adequately tested in HFpEF as the single large RCT of a beta-blocker which included $\mathrm{HFpEF}$ patients enrolled relatively few patients with $\mathrm{EF}>50 \%$ and, thus, was underpowered to address the effects of beta-blockers in HFpEF [38]. Aldosterone antagonists showed some benefit on diastolic function in a small single-center study [33], but had mixed effects in a larger 6-month, multicenter study of patients with fairly mild HFpEF, where symptoms, quality of life, and peak oxygen consumption did not improve and 6-min walk distance and renal function worsened despite favorable reductions in systolic blood pressure, $E / e^{\prime}, \mathrm{LV}$ mass, and BNP [36]. In the recently presented, but as yet unpublished, large multinational Treatment of Preserved Cardiac Function Heart Failure with an Aldosterone Antagonist (TOPCAT) trial, spironolactone did not reduce the primary composite endpoint of cardiovascular mortality, aborted cardiac arrest, and HF hospitalization, although the secondary endpoint of HF hospitalizations was modestly reduced with active therapy. In TOPCAT, there were striking differences in patient characteristics across sites, where very low event rates at some sites raised some concern over the accuracy of the HFpEF diagnosis. The reduction in HF but not all-cause hospitalizations may be related to the much higher incidence of renal dysfunction and hyperkalemia in the active therapy arm of TOPCAT. This raises concern over more general use in older HFpEF patients as marked increases in prescriptions for spironolactone in HF patients in the community after publication of the Randomized Aldactone Evaluation Study trial [101] were associated with proportional striking increases in hospitalizations for hyperkalemia and deaths [64]. Similar to the findings in TOPCAT, in a RCT of digoxin in HFpEF, there were trends toward fewer HF hospitalizations, but no effect on all-cause hospitalization due to proportional increases in acute coronary syndrome hospitalizations in the HFpEF sub-study of the Digitalis Investigator Group trial [2]. Nitrates are sometimes used for symptom relief in $\mathrm{HFpEF}$, but tolerance and effectiveness have never been studied in HFpEF. 


\section{Trials of novel therapies in HFpEF}

Animal studies and small studies in HFrEF patients suggested the potential for pleiotropic beneficial effects of PDE-5 inhibitors on multiple systems in HFpEF [103]. A small singlecenter study showed dramatic benefit of the PDE-5 inhibitor sildenafil on hemodynamics, $\mathrm{RV}$ function, and pulmonary function in HFpEF patients with mixed pulmonary hypertension and RV dysfunction [46]. However, a larger multicenter study in HFpEF patients with severe reduction in exercise capacity did not show benefit of sildenafil on exercise capacity, LV structure or function, symptoms, or clinical outcomes [104]. A sizable proof-of-concept study compared the effects of the dual angiotensin receptor-neprilysin inhibitor LCZ696 to ARB alone and showed reductions in BNP levels and atrial volume [118], suggesting the potential to impact clinical events in HFpEF. A larger outcomes-based trial of LCZ696 is being considered. The promising findings of the $\mathrm{I}_{f}$ channel inhibitor ivabradine were reviewed above [69], and a larger study in HFpEF in Europe is ongoing. As discussed above, an anti-inflammatory strategy testing the interleukin-1 antagonist anakinra in patients with HFpEF and elevated CRP levels showed benefit in a small proof-of-concept study [126].

\section{Non-medical therapy for HFpEF}

Four RCTs of exercise training in $\mathrm{HFpEF}$ each and collectively demonstrate that exercise training enhances exercise tolerance in HFpEF [121]. Given the high prevalence of obesity in HFpEF, the excessive cardiovascular demand and pro-inflammatory effect posed by morbid obesity, and the limited effectiveness of behavioral therapy for weight loss, bariatric surgery is an appealing potential therapy for obese HFpEF patients. While studies have shown that vascular and diastolic function improves with weight loss after bariatric surgery [128], no study has been performed in HFpEF. Disordered sleep breathing is common in $\mathrm{HFpEF}$ and requires therapy for symptom control, but effect on disease progression in HFrEF or HFpEF remains unclear. Device therapies such as cardiac resynchronization (CRT) or left ventricular assist devices are untested in HFpEF, although CRT could be considered for HFpEF patients with worsening symptoms after RV pacing for bradycardia indications. Gene and cell therapies are also untested in $\mathrm{HFpEF}$, but may hold promise in the future. In an aging rat model of diastolic dysfunction, adenoviral delivery of SERCA restored normal diastolic function, and a small clinical trial in HFrEF with adeno-associated viral delivery of SERCA showed beneficial short- and long-term effects in HFrEF, but to date, effects in HFpEF have not been tested [63, 109, 137].

\section{Gaps in knowledge and future directions}

The lack of an effective therapy for the epidemic of HFpEF represents a failure of our scientific and health care systems that must be rectified. Challenges in diagnosis and clinical trial design in HFpEF are not an excuse that can justify inaction when the economic burden and impact on patients are so clearly defined. Population demographic trends indicating marked increases in the aged population are well outlined, and the scientific community must adjust to the study and treatment of elderly persons with HFpEF and other morbid conditions as these are the patients that drive health care resource utilization. Clinicians need evidence-based approaches to HFpEF therapy in elderly persons. More collaboration 
between cardiovascular, gerontology, and aging disciplines is needed at the basic, translational, and clinical research levels to address the complexity of HFpEF and other diseases in the aging population. Epidemiology studies must continue to characterize the public health burden as there is evidence of continued increase in the burden of HFpEF and evolution of the phenotype. Clinical studies must continue to define the phenotype and integrative pathophysiology, refine diagnostic criteria, characterize unique subgroups, and test novel therapies in representative patient populations using both mechanistic and pragmatic study designs with patientcentric endpoints. Novel animal models incorporating age and multi-morbidity may advance the field, but there is an urgent need for safe methodologies to obtain myocardial tissue in HFpEF patients to define mechanisms and unifying disease paradigms that will guide the development and testing of preventative and therapeutic strategies.

\section{References}

1. Abudiab MM, Redfield MM, Melenovsky V, Olson TP, Kass DA, Johnson BD, Borlaug BA. Cardiac output response to exercise in relation to metabolic demand in heart failure with preserved ejection fraction. Eur J Heart Fail. 2013; 15:776-785. [PubMed: 23426022]

2. Ahmed A, Rich MW, Fleg JL, Zile MR, Young JB, Kitzman DW, Love TE, Aronow WS, Adams KFJ, Gheorghiade M. Effects of digoxin on morbidity and mortality in diastolic heart failure: the Ancillary Digitalis Investigation Group trial. Circulation. 2006; 114:397-403. [PubMed: 16864724]

3. Andersen MJ, Ersboll M, Axelsson A, Gustafsson F, Hassager C, Kober L, Borlaug BA, Boesgaard S, Skovgaard LT, Moller JE. Sildenafil and diastolic dysfunction after acute myocardial infarction in patients with preserved ejection fraction: the Sildenafil and Diastolic Dysfunction After Acute Myocardial Infarction (SIDAMI) trial. Circulation. 2013; 127:1200-1208. [PubMed: 23406672]

4. Aronow WS, Ahn C, Kronzon I. Effect of propranolol versus no propranolol on total mortality plus nonfatal myocardial infarction in older patients with prior myocardial infarction, congestive heart failure, and left ventricular ejection fraction $>$ or $=40 \%$ treated with diuretics plus angiotensinconverting enzyme inhibitors. Am J Cardiol. 1997; 80:207-209. [PubMed: 9230162]

5. Ather S, Chan W, Bozkurt B, Aguilar D, Ramasubbu K, Zachariah AA, Wehrens XH, Deswal A. Impact of noncardiac comorbidities on morbidity and mortality in a predominantly male population with heart failure and preserved versus reduced ejection fraction. J Am Coll Cardiol. 2012; 59:9981005. [PubMed: 22402071]

6. Bhatia RS, Tu JV, Lee DS, Austin PC, Fang J, Haouzi A, Gong Y, Liu PP. Outcome of heart failure with preserved ejection fraction in a population-based study. N Engl J Med. 2006; 355:260-269. [PubMed: 16855266]

7. Bishu K, Hamdani N, Kruger M, Mohammed SF, Ohtani T, Abdalrhim A, Ogut O, Burnett JC, Linke WA, Redfield MM. cGMP enhancing therapy improves LV diastolic distensibility by phosphorylating titin. Circulation. 2010; 122:A8754.

8. Boilson BA, Schirger JA, Borlaug BA. Caveat medicus! Pulmonary hypertension in the elderly: a word of caution. Eur J Heart Fail. 2010; 12:89-93. [PubMed: 20023048]

9. Borbély A, van der Velden J, PAPP Z, Bronzwaer JG, Edes I, Stienen GJ, Paulus WJ. Cardiomyocyte stiffness in diastolic heart failure. Circulation. 2005; 111:774-781. [PubMed: 15699264]

10. Borbély A, Falcao-Pires I, van Heerebeek L, et al. Hypophosphorylation of the Stiff N2B titin isoform raises cardio-myocyte resting tension in failing human myocardium. Circ Res. 2009; 104:780-786. [PubMed: 19179657]

11. Borlaug BA, Kass DA. Ventricular-vascular interaction in heart failure. Heart Fail Clin. 2008; 4:23-36. [PubMed: 18313622]

12. Borlaug BA, Paulus WJ. Heart failure with preserved ejection fraction: pathophysiology, diagnosis, and treatment. Eur Heart J. 2011; 32:670-679. [PubMed: 21138935] 
13. Borlaug BA, Redfield MM. Diastolic and systolic heart failure are distinct phenotypes within the heart failure spectrum. Circulation. 2011; 123:2006-2014. [PubMed: 21555723]

14. Borlaug BA, Jaber WA, Ommen SR, Lam CS, Redfield MM, Nishimura RA. Diastolic relaxation and compliance reserve during dynamic exercise in heart failure with preserved ejection fraction. Heart. 2011; 97:964-969. [PubMed: 21478380]

15. Borlaug BA, Lam CS, Roger VL, Rodeheffer RJ, Redfield MM. Contractility and ventricular systolic stiffening in hypertensive heart disease insights into the pathogenesis of heart failure with preserved ejection fraction. J Am Coll Cardiol. 2009; 54:410-418. [PubMed: 19628115]

16. Borlaug BA, Melenovsky V, Russell SD, Kessler K, Pacak K, Becker LC, Kass DA. Impaired chronotropic and vasodilator reserves limit exercise capacity in patients with heart failure and a preserved ejection fraction. Circulation. 2006; 114:2138-2147. [PubMed: 17088459]

17. Borlaug BA, Nishimura RA, Sorajja P, Lam CS, Redfield MM. Exercise hemodynamics enhance diagnosis of early heart failure with preserved ejection fraction. Circ Heart Fail. 2010; 3:588-595. [PubMed: 20543134]

18. Borlaug BA, Olson TP, Lam CS, Flood KS, Lerman A, Johnson BD, Redfield MM. Global cardiovascular reserve dysfunction in heart failure with preserved ejection fraction. J Am Coll Cardiol. 2010; 56:845-854. [PubMed: 20813282]

19. Borlaug BA, Redfield MM, Melenovsky V, Kane GC, Karon BL, Jacobsen SJ, Rodeheffer RJ. Longitudinal changes in left ventricular stiffness: a community-based study. Circ Heart Fail. 2013; 6:944-952. [PubMed: 23811963]

20. Borlaug BA, Sorajja P, Nishimura RA, Lam CSP, Redfield MM. Do exercise hemodynamics enhance diagnosis of heart failure with preserved ejection fraction? Circulation. 2009; 120:S756.

21. Brouwers FP, de Boer RA, van der Harst P, Voors AA, Gansevoort RT, Bakker SJ, Hillege HL, van Veldhuisen DJ, van Gilst WH. Incidence and epidemiology of new onset heart failure with preserved vs. reduced ejection fraction in a community-based cohort: 11-year follow-up of PREVEND. Eur Heart J. 2013; 34:1424-1431. [PubMed: 23470495]

22. Brubaker PH, Kitzman DW. Chronotropic incompetence: causes, consequences, and management. Circulation. 2011; 123:1010-1020. [PubMed: 21382903]

23. Brubaker PH, Joo KC, Stewart KP, Fray B, Moore B, Kitzman DW. Chronotropic incompetence and its contribution to exercise intolerance in older heart failure patients. J Cardiopulm Rehabil. 2006; 26:86-89. [PubMed: 16569976]

24. Burchfield JS, Xie M, Hill JA. Pathological ventricular remodeling: mechanisms: part 1 of 2. Circulation. 2013; 128:388-400. [PubMed: 23877061]

25. Burke MA, Katz DH, Beussink L, et al. Prognostic importance of pathophysiologic markers in patients with heart failure and preserved ejection fraction. Circ Heart Fail. 2013

26. Burkhoff D, Mirsky I, Suga H. Assessment of systolic and diastolic ventricular properties via pressure-volume analysis: a guide for clinical, translational, and basic researchers. Am J Physiol Heart Circ Physiol. 2005; 289:H501-H512. [PubMed: 16014610]

27. Bursi F, Weston SA, Redfield MM, Jacobsen SJ, Pakhomov S, Nkomo VT, Meverden RA, Roger VL. Systolic and diastolic heart failure in the community. JAMA. 2006; 296:2209-2216. [PubMed: 17090767]

28. Campbell RT, Jhund PS, Castagno D, Hawkins NM, Petrie MC, McMurray JJ. What have we learned about patients with heart failure and preserved ejection fraction from DIG-PEF, CHARMpreserved, and I-PRESERVE? J Am Coll Cardiol. 2012; 60:2349-2356. [PubMed: 23141494]

29. Choudhury L, Gheorghiade M, Bonow RO. Coronary artery disease in patients with heart failure and preserved systolic function. Am J Cardiol. 2002; 89:719-722. [PubMed: 11897215]

30. Colin P, Ghaleh B, Hittinger L, Monnet X, Slama M, Giudicelli JF, Berdeaux A. Differential effects of heart rate reduction and beta-blockade on left ventricular relaxation during exercise. Am J Physiol Heart Circ Physiol. 2002; 282:H672-H679. [PubMed: 11788417]

31. Dauterman K, Pak PH, Maughan WL, Nussbacher A, Ariê S, Liu CP, Kass DA. Contribution of external forces to left ventricular diastolic pressure. Implications for the clinical use of the Starling law. Ann Intern Med. 1995; 122:737-742. [PubMed: 7717595] 
32. De Keulenaer GW, Brutsaert DL. Systolic and diastolic heart failure are overlapping phenotypes within the heart failure spectrum. Circulation. 2011; 123:1996-2004. discussion 2005. [PubMed: 21555722]

33. Deswal A, Richardson P, Bozkurt B, Mann DL. Results of the Randomized Aldosterone Antagonism in Heart Failure with Preserved Ejection Fraction trial (RAAM-PEF). J Card Fail. 2011; 17:634-642. [PubMed: 21807324]

34. Dunlay SM, Roger VL, Weston SA, Jiang R, Redfield MM. Longitudinal changes in ejection fraction in heart failure patients with preserved and reduced ejection fraction. Circ Heart Fail. 2012; 5:720-726. [PubMed: 22936826]

35. Edelmann F, Stahrenberg R, Gelbrich G, et al. Contribution of comorbidities to functional impairment is higher in heart failure with preserved than with reduced ejection fraction. Clin Res Cardiol. 2011; 100:755-764. [PubMed: 21416189]

36. Edelmann F, Wachter R, Schmidt AG, et al. Effect of spironolactone on diastolic function and exercise capacity in patients with heart failure with preserved ejection fraction: the Aldo- DHF randomized controlled trial. JAMA. 2013; 309:781-791. [PubMed: 23443441]

37. Ennezat PV, Lefetz Y, Maréchaux S, et al. Left ventricular abnormal response during dynamic exercise in patients with heart failure and preserved left ventricular ejection fraction at rest. J Card Fail. 2008; 14:475-480. [PubMed: 18672195]

38. Flather MD, Shibata MC, Coats AJ, et al. Randomized trial to determine the effect of nebivolol on mortality and cardiovascular hospital admission in elderly patients with heart failure (SENIORS). Eur Heart J. 2005; 26:215-225. [PubMed: 15642700]

39. Freiburg A, Trombitas K, Hell W, et al. Series of exonskipping events in the elastic spring region of titin as the structural basis for myofibrillar elastic diversity. Circ Res. 2000; 86:1114-1121. [PubMed: 10850961]

40. Fukuda N, Wu Y, Nair P, Granzier HL. Phosphorylation of titin modulates passive stiffness of cardiac muscle in a titin isoform-dependent manner. J Gen Physiol. 2005; 125:257-271. [PubMed: 15738048]

41. Fukuta H, Sane DC, Brucks S, Little WC. Statin therapy may be associated with lower mortality in patients with diastolic heart failure: a preliminary report. Circulation. 2005; 112:357-363. [PubMed: 16009792]

42. Gandhi SK, Powers JC, Nomeir AM, Fowle K, Kitzman DW, Rankin KM, Little WC. The pathogenesis of acute pulmonary edema associated with hypertension. N Engl J Med. 2001; 344:17-22. [PubMed: 11136955]

43. Gillebert TC, Leite-Moreira AF, De Hert SG. Load dependent diastolic dysfunction in heart failure. Heart Fail Rev. 2000; 5:345-355. [PubMed: 11498648]

44. Gradman AH, Wilson JT. Hypertension and diastolic heart failure. Curr Cardiol Rep. 2009; 11:422-429. [PubMed: 19863866]

45. Grutzner A, Garcia-Manyes S, Kotter S, Badilla CL, Fernandez JM, Linke WA. Modulation of titin-based stiffness by disulfide bonding in the cardiac titin N2-B unique sequence. Biophys J. 2009; 97:825-834. [PubMed: 19651040]

46. Guazzi M, Vicenzi M, Arena R, Guazzi MD. Pulmonary hypertension in heart failure with preserved ejection fraction: a target of phosphodiesterase-5 inhibition in a 1-year study. Circulation. 2011; 124:164-174. [PubMed: 21709061]

47. Guo W, Schafer S, Greaser ML, et al. RBM20, a gene for hereditary cardiomyopathy, regulates titin splicing. Nat Med. 2012; 18:766-773. [PubMed: 22466703]

48. Ha JW, Chung N, Jang Y, Kang WC, Kang SM, Rim SJ, Shim WH, Cho SY, Kim SS. Is the left atrial v. wave the determinant of peak pulmonary artery pressure in patients with pure mitral stenosis? Am J Cardiol. 2000; 85:986-991. [PubMed: 10760340]

49. Hamdani N, Krysiak J, Kreusser MM, Neef S, Dos Remedios CG, Maier LS, Kruger M, Backs J, Linke WA. Crucial role for Ca2(+)/calmodulin-dependent protein kinase-II in regulating diastolic stress of normal and failing hearts via titin phosphorylation. Circ Res. 2013; 112:664-674.

[PubMed: 23283722] 
50. Hay I, Rich J, Ferber P, Burkhoff D, Maurer MS. Role of impaired myocardial relaxation in the production of elevated left ventricular filling pressure. Am J Physiol Heart Circ Physiol. 2005; 288:H1203-H1208. [PubMed: 15498827]

51. Henkel DM, Redfield MM, Weston SA, Gerber Y, Roger VL. Death in heart failure: a community perspective. Circ Heart Fail. 2008; 1:91-97. [PubMed: 19300532]

52. Herman DS, Lam L, Taylor MR, et al. Truncations of titin causing dilated cardiomyopathy. N Engl J Med. 2012; 366:619-628. [PubMed: 22335739]

53. Hidalgo CG, Chung CS, Saripalli C, Methawasin M, Hutchinson KR, Tsaprailis G, Labeit S, Mattiazzi A, Granzier HL. The multifunctional $\mathrm{Ca}(2+) /$ calmodulin-dependent protein kinase II delta (CaMKIIdelta) phosphorylates cardiac titin's spring elements. J Mol Cell Cardiol. 2013; 54:90-97. [PubMed: 23220127]

54. Hidalgo C, Hudson B, Bogomolovas J, Zhu Y, Anderson B, Greaser M, Labeit S, Granzier H. PKC phosphorylation of titin's PEVK element: a novel and conserved pathway for modulating myocardial stiffness. Circ Res. 2009; 105:631-638. [PubMed: 19679839]

55. Hoenig MR, Bianchi C, Rosenzweig A, Sellke FW. The cardiac microvasculature in hypertension, cardiac hypertrophy and diastolic heart failure. Curr Vasc Pharmacol. 2008; 6:292-300. [PubMed: 18855717]

56. Hoit BD. Left atrial size and function: role in prognosis. J Am Coll Cardiol. 2013

57. Hoshijima M, Ikeda Y, Iwanaga Y, et al. Chronic suppression of heart-failure progression by a pseudophosphorylated mutant of phospholamban via in vivo cardiac rAAV gene delivery. Nat Med. 2002; 8:864-871. [PubMed: 12134142]

58. Hudson BD, Hidalgo CG, Gotthardt M, Granzier HL. Excision of titin's cardiac PEVK spring element abolishes PKCalpha-induced increases in myocardial stiffness. J Mol Cell Cardiol. 2010; 48:972-978. [PubMed: 20026128]

59. Hundley WG, Kitzman DW, Morgan TM, Hamilton CA, Darty SN, Stewart KP, Herrington DM, Link KM, Little WC. Cardiac cycle-dependent changes in aortic area and distensibility are reduced in older patients with isolated diastolic heart failure and correlate with exercise intolerance. J Am Coll Cardiol. 2001; 38:796-802. [PubMed: 11527636]

60. Ismahil MA, Hamid T, Bansal SS, Patel B, Kingery JR, Prabhu SD. Remodeling of the mononuclear phagocyte network underlies chronic inflammation and disease progression in heart failure: critical importance of the cardiosplenic axis. Circ Res. 2014; 114:266-282. [PubMed: 24186967]

61. Iwanaga Y, Nishi I, Furuichi S, Noguchi T, Sase K, Kihara Y, Goto Y, Nonogi H. B-type natriuretic peptide strongly reflects diastolic wall stress in patients with chronic heart failure: comparison between systolic and diastolic heart failure. J Am Coll Cardiol. 2006; 47:742-748. [PubMed: 16487838]

62. Jaber W, Maniu CV, Krysiak J, Shapiro BP, Meyer DM, Linke WA, Redfield MM. Titin isoforms, extracellular matrix, and global chamber remodeling in experimental dilated cardiomyopathy: functional implications and mechanistic insights. Circ Heart Fail. 2008; 1:192-199. [PubMed: 19808289]

63. Jessup M, Greenberg B, Mancini D, et al. Calcium Upregulation by Percutaneous Administration of Gene Therapy in Cardiac Disease (CUPID): a phase 2 trial of intracoronary gene therapy of sarcoplasmic reticulum $\mathrm{Ca}^{2+}$-ATPase in patients with advanced heart failure. Circulation. 2011; 124:304-313. [PubMed: 21709064]

64. Juurlink DN, Mamdani MM, Lee DS, Kopp A, Austin PC, Laupacis A, Redelmeier DA. Rates of hyperkalemia after publication of the Randomized Aldactone Evaluation Study. N Engl J Med. 2004; 351:543-551. [PubMed: 15295047]

65. Kasner M, Westermann D, Lopez B, Gaub R, Escher F, Kuhl U, Schultheiss HP, Tschope C. Diastolic tissue Doppler indexes correlate with the degree of collagen expression and cross-linking in heart failure and normal ejection fraction. J Am Coll Cardiol. 2011; 57:977-985. [PubMed: 21329845]

66. Kawaguchi M, Hay I, Fetics B, Kass DA. Combined ventricular systolic and arterial stiffening in patients with heart failure and preserved ejection fraction: implications for systolic and diastolic reserve limitations. Circulation. 2003; 107:714-720. [PubMed: 12578874] 
67. Kaye DM, Hoshijima M, Chien KR. Reversing advanced heart failure by targeting $\mathrm{Ca}^{2+}$ cycling. Annu Rev Med. 2008; 59:13-28. [PubMed: 18186701]

68. Kitzman DW, Little WC, Brubaker PH, Anderson RT, Hundley WG, Marburger CT, Brosnihan B, Morgan TM, Stewart KP. Pathophysiological characterization of isolated diastolic heart failure in comparison to systolic heart failure. JAMA. 2002; 288:2144-2150. [PubMed: 12413374]

69. Kosmala W, Holland DJ, Rojek A, Wright L, Przewlocka-Kosmala M, Marwick TH. Effect of Ifchannel inhibition on hemodynamic status and exercise tolerance in heart failure with preserved ejection fraction: a randomized trial. J Am Coll Cardiol. 2013; 62:1330-1338. [PubMed: 23916925]

70. Kramer K, Kirkman P, Kitzman D, Little WC. Flash pulmonary edema: association with hypertension and reoccurrence despite coronary revascularization. Am Heart J. 2000; 140:451455. [PubMed: 10966547]

71. Kranias EG, Hajjar RJ. Modulation of cardiac contractility by the phospholamban/SERCA2a regulatome. Circ Res. 2012; 110:1646-1660. [PubMed: 22679139]

72. Kruger M, Linke WA. Protein kinase-A phosphorylates titin in human heart muscle and reduces myofibrillar passive tension. J Muscle Res Cell Motil. 2006; 27:435-444. [PubMed: 16897574]

73. Kruger M, Linke WA. Titin-based mechanical signalling in normal and failing myocardium. J Mol Cell Cardiol. 2009; 46:490-498. [PubMed: 19639676]

74. Kruger M, Linke WA. The giant protein titin: a regulatory node that integrates myocyte signaling pathways. J Biol Chem. 2011; 286:9905-9912. [PubMed: 21257761]

75. Kruger M, Babicz K, von Frieling-Salewsky M, Linke WA. Insulin signaling regulates cardiac titin properties in heart development and diabetic cardiomyopathy. J Mol Cell Cardiol. 2010; 48:910916. [PubMed: 20184888]

76. Kruger M, Sachse C, Zimmermann WH, Eschenhagen T, Klede S, Linke WA. Thyroid hormone regulates developmental titin isoform transitions via the PI3K/AKT pathway. Circ Res. 2008; 102:439-447. [PubMed: 18096819]

77. Krüger M, Kötter S, Grützner A, Lang P, Andresen C, Redfield MM, Butt E, dos Remedios CG, Linke WA. Protein kinase G modulates human myocardial passive stiffness by phosphorylation of the titin springs. Circ Res. 2009; 104:87-94. [PubMed: 19023132]

78. Lakatta EG, Levy D. Arterial and cardiac aging: major shareholders in cardiovascular disease enterprises: Part I: aging arteries: a " set up” for vascular disease. Circulation. 2003; 107:139-146. [PubMed: 12515756]

79. Lakatta EG, Levy D. Arterial and cardiac aging: major shareholders in cardiovascular disease enterprises: Part II: the aging heart in health: links to heart disease. Circulation. 2003; 107:346354. [PubMed: 12538439]

80. Lam CS, Roger VL, Rodeheffer RJ, Borlaug BA, Enders FT, Redfield MM. Pulmonary hypertension in heart failure with preserved ejection fraction: a community-based study. J Am Coll Cardiol. 2009; 53:1119-1126. [PubMed: 19324256]

81. Lam CS, Roger VL, Rodeheffer RJ, Bursi F, Borlaug BA, Ommen SR, Kass DA, Redfield MM. Cardiac structure and ventricular-vascular function in persons with heart failure and preserved ejection fraction from Olmsted County, Minnesota. Circulation. 2007; 115:1982-1990. [PubMed: 17404159]

82. Lamas GA, Knight JD, Sweeney MO, et al. Impact of rate-modulated pacing on quality of life and exercise capacity - evidence from the Advanced Elements of Pacing Randomized Controlled Trial (ADEPT). Heart Rhythm. 2007; 4:1125-1132. [PubMed: 17765608]

83. Linke WA, Bucker S. King of hearts: a splicing factor rules cardiac proteins. Nat Med. 2012; 18:660-661. [PubMed: 22561820]

84. Makarenko I, Opitz CA, Leake MC, Neagoe C, Kulke M, Gwathmey JK, del Monte F, Hajjar RJ, Linke WA. Passive stiffness changes caused by upregulation of compliant titin isoforms in human dilated cardiomyopathy hearts. Circ Res. 2004; 95:708-716. [PubMed: 15345656]

85. McMurray JJ, Adamopoulos S, Anker SD, et al. ESC guidelines for the diagnosis and treatment of acute and chronic heart failure 2012: the Task Force for the Diagnosis and Treatment of Acute and Chronic Heart Failure 2012 of the European Society of Cardiology. Developed in collaboration 
with the Heart Failure Association (HFA) of the ESC. Eur J Heart Fail. 2012; 14:803-869. [PubMed: 22828712]

86. Melenovsky V, Borlaug BA, Rosen B, Hay I, Ferruci L, Morell CH, Lakatta EG, Najjar SS, Kass DA. Cardiovascular features of heart failure with preserved ejection fraction versus nonfailing hypertensive left ventricular hypertrophy in the urban Baltimore community: the role of atrial remodeling/dysfunction. J Am Coll Cardiol. 2007; 49:198-207. [PubMed: 17222731]

87. Micha R, Imamura F, Wyler von Ballmoos M, Solomon DH, Hernan MA, Ridker PM, Mozaffarian D. Systematic review and meta-analysis of methotrexate use and risk of cardiovascular disease. Am J Cardiol. 2011; 108:1362-1370. [PubMed: 21855836]

88. Mohammed SF, Borlaug BA, Roger VL, Mirzoyev SA, Rodeheffer RJ, Chirinos JA, Redfield MM. Comorbidity and ventricular and vascular structure and function in heart failure with preserved ejection fraction: a community based study. Circ Heart Fail. 2012; 5:710-719. [PubMed: 23076838]

89. Nagueh SF, Shah G, Wu Y, Torre-Amione G, King NM, Lahmers S, Witt CC, Becker K, Labeit S, Granzier HL. Altered titin expression, myocardial stiffness, and left ventricular function in patients with dilated cardiomyopathy. Circulation. 2004; 110:155-162. [PubMed: 15238456]

90. Neagoe C, Kulke M, del Monte F, Gwathmey JK, de Tombe PP, Hajjar RJ, Linke WA. Titin isoform switch in ischemic human heart disease. Circulation. 2002; 106:1333-1341. [PubMed: 12221049]

91. Norman HS, Oujiri J, Larue SJ, Chapman CB, Margulies KB, Sweitzer NK. Decreased cardiac functional reserve in heart failure with preserved systolic function. J Card Fail. 2011; 17:301-308. [PubMed: 21440868]

92. Ommen SR, Nishimura RA, Appleton CP, Miller FA, Oh JK, Redfield MM, Tajik AJ. Clinical utility of Doppler echocardiography and tissue Doppler imaging in the estimation of left ventricular filling pressures: a comparative simultaneous Doppler-catheterization study. Circulation. 2000; 102:1788-1794. [PubMed: 11023933]

93. Owan TE, Redfield MM. Epidemiology of diastolic heart failure. Prog Cardiovasc Dis. 2005; 47:320-332. [PubMed: 16003647]

94. Owan TE, Hodge DO, Herges RM, Jacobsen SJ, Roger VL, Redfield MM. Trends in prevalence and outcome of heart failure with preserved ejection fraction. N Engl J Med. 2006; 355:251-259. [PubMed: 16855265]

95. Packer M. Can brain natriuretic peptide be used to guide the management of patients with heart failure and a preserved ejection fraction? The wrong way to identify new treatments for a nonexistent disease. Circ Heart Fail. 2011; 4:538-540. [PubMed: 21934089]

96. Paulus WJ, Tschope C. A novel paradigm for heart failure with preserved ejection fraction: comorbidities drive myocardial dysfunction and remodeling through coronary microvascular endothelial inflammation. J Am Coll Cardiol. 2013; 62:263-271. [PubMed: 23684677]

97. Paulus WJ, Vantrimpont PJ, Shah AM. Acute effects of nitric oxide on left ventricular relaxation and diastolic distensibility in humans: assessment by bicoronary sodium nitroprusside infusion. Circulation. 1994; 89:2070-2078. [PubMed: 7910117]

98. Perrino C, Naga Prasad SV, Mao L, Noma T, Yan Z, Kim HS, Smithies O, Rockman HA. Intermittent pressure overload triggers hypertrophy-independent cardiac dysfunction and vascular rarefaction. J Clin Invest. 2006; 116:1547-1560. [PubMed: 16741575]

99. Phan TT, Abozguia K, Nallur Shivu G, et al. Heart failure with preserved ejection fraction is characterized by dynamic impairment of active relaxation and contraction of the left ventricle on exercise and associated with myocardial energy deficiency. J Am Coll Cardiol. 2009; 54:402-409. [PubMed: 19628114]

100. Phan TT, Nallur Shivu G, Abozguia K, Davies C, Nassimizadeh M, Jimenez D, Weaver R, Ahmed I, Frenneaux M. Impaired heart rate recovery and chronotropic incompetence in patients with heart failure with preserved ejection fraction. Circ Heart Fail. 2009; 3:29-34. [PubMed: 19917649]

101. Pitt B, Zannad F, Remme WJ, Cody R, Castaigne A, Perez A, Palensky J, Wittes J. The effect of spironolactone on morbidity and mortality in patients with severe heart failure. Randomized 
Aldactone Evaluation Study Investigators. N Engl J Med. 1999; 341:709-717. [PubMed: 10471456]

102. Raskin A, Lange S, Banares K, et al. A novel mechanism involving four-and-a-half LIM domain protein-1 and extracellular signal-regulated kinase-2 regulates titin phosphorylation and mechanics. J Biol Chem. 2012; 287:29273-29284. [PubMed: 22778266]

103. Redfield MM, Borlaug BA, Lewis GD, et al. PhosphdiesteRasE-5 Inhibition to Improve CLinical Status and EXercise Capacity in Diastolic Heart Failure (RELAX) trial: rationale and design. Circ Heart Fail. 2012; 5:653-659. [PubMed: 22991405]

104. Redfield MM, Chen HH, Borlaug BA, et al. Effect of phosphodiesterase-5 inhibition on exercise capacity and clinical status in heart failure with preserved ejection fraction: a randomized clinical trial. JAMA. 2013; 309:1268-1277. [PubMed: 23478662]

105. Redfield MM, Jacobsen SJ, Burnett JCJ, Mahoney DW, Bailey KR, Rodeheffer RJ. Burden of systolic and diastolic ventricular dysfunction in the community: appreciating the scope of the heart failure epidemic. JAMA. 2003; 289:194-202. [PubMed: 12517230]

106. Reil JC, Tardif JC, Ford I, Lloyd SM, O'Meara E, Komajda M, Borer JS, Tavazzi L, Swedberg K, Böhm M. Selective heart rate reduction with ivabradine unloads the left ventricle in heart failure patients. J Am Coll Cardiol. 2013; 62:1977-1985. [PubMed: 23933545]

107. Sakata S, Lebeche D, Sakata N, et al. Targeted gene transfer increases contractility and decreases oxygen cost of contractility in normal rat hearts. Am J Physiol Heart Circ Physiol. 2007; 292:H2356-H2363. [PubMed: 17220178]

108. Sasayama S, Nonogi H, Miyazaki S, Sakurai T, Kawai C, Eiho S, Kuwahara M. Changes in diastolic properties of regional myocardium during pacing-induced ischemia in human subjects. J Am Coll Cardiol. 1985; 5:599-606. [PubMed: 3973256]

109. Schmidt U, del Monte F, Miyamoto MH, Matsui T, Gwathmey JK, Rosenzweig A, Hajjar RJ. Restoration of diastolic function in senescent rat hearts through adenoviral gene transfer of sarcoplasmic reticulum Ca(2+)-ATPase. Circulation. 2000; 101:790-796. [PubMed: 10683354]

110. Schultz JLJ, Glascock BJ, Witt SA, Nieman ML, Nattamai KJ, Liu LH, Lorenz JN, Shull GE, Kimball TR, Periasamy M. Accelerated onset of heart failure in mice during pressure overload with chronically decreased SERCA2 calcium pump activity. Am J Physiol Heart Circ Physiol. 2004; 286:H1146-H1153. [PubMed: 14630633]

111. Schwammenthal E, Vered Z, Agranat O, Kaplinsky E, Rabinowitz B, Feinberg MS. Impact of atrioventricular compliance on pulmonary artery pressure in mitral stenosis: an exercise echocardiographic study. Circulation. 2000; 102:2378-2384. [PubMed: 11067792]

112. Schwartzenberg S, Redfield MM, From AM, Sorajja P, Nishimura RA, Borlaug BA. Effects of vasodilation in heart failure with preserved or reduced ejection fraction implications of distinct pathophysiologies on response to therapy. J Am Coll Cardiol. 2012; 59:442-451. [PubMed: 22281246]

113. Shah RV, Desai AS, Givertz MM. The effect of renin-angiotensin system inhibitors on mortality and heart failure hospitalization in patients with heart failure and preserved ejection fraction: a systematic review and meta-analysis. J Card Fail. 2010; 16:260-267. [PubMed: 20206902]

114. Shah SJ, Gheorghiade M. Heart failure with preserved ejection fraction: treat now by treating comorbidities. JAMA. 2008; 300:431-433. [PubMed: 18647986]

115. Shapiro BP, Lam CS, Patel JB, Mohammed SF, Kruger M, Meyer DM, Linke WA, Redfield MM. Acute and chronic ventricular-arterial coupling in systole and diastole: insights from an elderly hypertensive model. Hypertension. 2007; 50:503-511. [PubMed: 17620524]

116. Shiojima I, Sato K, Izumiya Y, Schiekofer S, Ito M, Liao R, Colucci WS, Walsh K. Disruption of coordinated cardiac hypertrophy and angiogenesis contributes to the transition to heart failure. $\mathrm{J}$ Clin Invest. 2005; 115:2108-2118. [PubMed: 16075055]

117. Solomon SD, Janardhanan R, Verma A, et al. Effect of angiotensin receptor blockade and antihypertensive drugs on diastolic function in patients with hypertension and diastolic dysfunction: a randomised trial. Lancet. 2007; 369:2079-2087. [PubMed: 17586303]

118. Solomon SD, Zile M, Pieske B, et al. The angiotensin receptor neprilysin inhibitor LCZ696 in heart failure with preserved ejection fraction: a phase 2 double-blind randomised controlled trial. Lancet. 2012; 380:1387-1395. [PubMed: 22932717] 
119. Stehle R, Solzin J, Iorga B, Poggesi C. Insights into the kinetics of $\mathrm{Ca}^{2+}$-regulated contraction and relaxation frommyofibril studies. Pflugers Arch. 2009; 458:337-357. [PubMed: 19165498]

120. Steinberg BA, Zhao X, Heidenreich PA, Peterson ED, Bhatt DL, Cannon CP, Hernandez AF, Fonarow GC, Investigators GWTGSA CA. Trends in patients hospitalized with heart failure and preserved left ventricular ejection fraction: prevalence, therapies, and outcomes. Circulation. 2012; 126:65-75. [PubMed: 22615345]

121. Taylor RS, Davies EJ, Dalal HM, Davis R, Doherty P, Cooper C, Holland DJ, Jolly K, Smart NA. Effects of exercise training for heart failure with preserved ejection fraction: a systematic review and meta-analysis of comparative studies. Int J Cardiol. 2012; 162:6-13. [PubMed: 22664368]

122. Tedford RJ, Hassoun PM, Mathai SC, et al. Pulmonary capillary wedge pressure augments right ventricular pulsatile loading. Circulation. 2012; 125:289-297. [PubMed: 22131357]

123. van Heerebeek L, Borbély A, Niessen HW, Bronzwaer JG, van der Velden J, Stienen GJ, Linke WA, Laarman GJ, Paulus WJ. Myocardial structure and function differ in systolic and diastolic heart failure. Circulation. 2006; 113:1966-1973. [PubMed: 16618817]

124. van Heerebeek L, Hamdani N, Falcao-Pires I, et al. Low myocardial protein kinase G activity in heart failure with preserved ejection fraction. Circulation. 2012; 126:830-839. [PubMed: 22806632]

125. van Heerebeek L, Hamdani N, Handoko ML, et al. Diastolic stiffness of the failing diabetic heart: importance of fibrosis, advanced glycation end products, and myocyte resting tension. Circulation. 2008; 117:43-51. [PubMed: 18071071]

126. Van Tassell BW, Arena R, Biondi-Zoccai G, et al. Effects of interleukin-1 blockade with anakinra on aerobic exercise capacity in patients with heart failure and preserved ejection fraction (from the D-HART Pilot Study). Am J Cardiol. 2014; 113:321-327. [PubMed: 24262762]

127. Verma A, Solomon SD. Diastolic dysfunction as a link between hypertension and heart failure. Med Clin N Am. 2009; 93:647-664. [PubMed: 19427497]

128. Vest AR, Heneghan HM, Agarwal S, Schauer PR, Young JB. Bariatric surgery and cardiovascular outcomes: a systematic review. Heart. 2012; 98:1763-1777. [PubMed: 23077152]

129. Westermann D, Lindner D, Kasner M, et al. Cardiac inflammation contributes to changes in the extracellular matrix in patients with heart failure and normal ejection fraction. Circ Heart Fail. 2011; 4:44-52. [PubMed: 21075869]

130. Yamamoto K, Burnett JCJ, Redfield MM. Effect of endogenous natriuretic peptide system on ventricular and coronary function in failing heart. Am J Physiol. 1997; 273:H2406-H2414. [PubMed: 9374778]

131. Yancy CW, Jessup M, Bozkurt B, et al. 2013 ACCF/AHA guideline for the management of heart failure: a report of the American College of Cardiology Foundation/American Heart Association Task Force on practice guidelines. Circulation. 2013; 128:e240-e319. [PubMed: 23741058]

132. Zakeri R, Borlaug BA, McNulty S, et al. Impact of atrial fibrillation on exercise capacity in heart failure with preserved ejection fraction: a RELAX trial ancillary study. Circ Heart Fail. 2013; 7:123-130. [PubMed: 24162898]

133. Zakeri R, Chamberlain AM, Roger VL, Redfield MM. Temporal relationship and prognostic significance of atrial fibrillation in heart failure patients with preserved ejection fraction: a community-based study. Circulation. 2013; 128:1085-1093. [PubMed: 23908348]

134. Zile MR, Brutsaert DL. New concepts in diastolic dysfunction and diastolic heart failure: Part II: causal mechanisms and treatment. Circulation. 2002; 105:1503-1508. [PubMed: 11914262]

135. Zile MR, Baicu CF, Gaasch WH. Diastolic heart failure-abnormalities in active relaxation and passive stiffness of the left ventricle. N Engl J Med. 2004; 350:1953-1959. [PubMed: 15128895]

136. Zile MR, Gottdiener JS, Hetzel SJ, McMurray JJ, Komajda M, McKelvie R, Baicu CF, Massie $\mathrm{BM}$, Carson PE. Prevalence and significance of alterations in cardiac structure and function in patients with heart failure and a preserved ejection fraction. Circulation. 2011; 124:2491-2501. [PubMed: 22064591]

137. Zsebo K, Yaroshinsky A, Rudy JJ, Wagner K, Greenberg B, Jessup M, Hajjar RJ. Long-term effects of AAV1/SERCA2a gene transfer in patients with severe heart failure: analysis of recurrent cardiovascular events and mortality. Circ Res. 2014; 114:101-108. [PubMed: 24065463] 


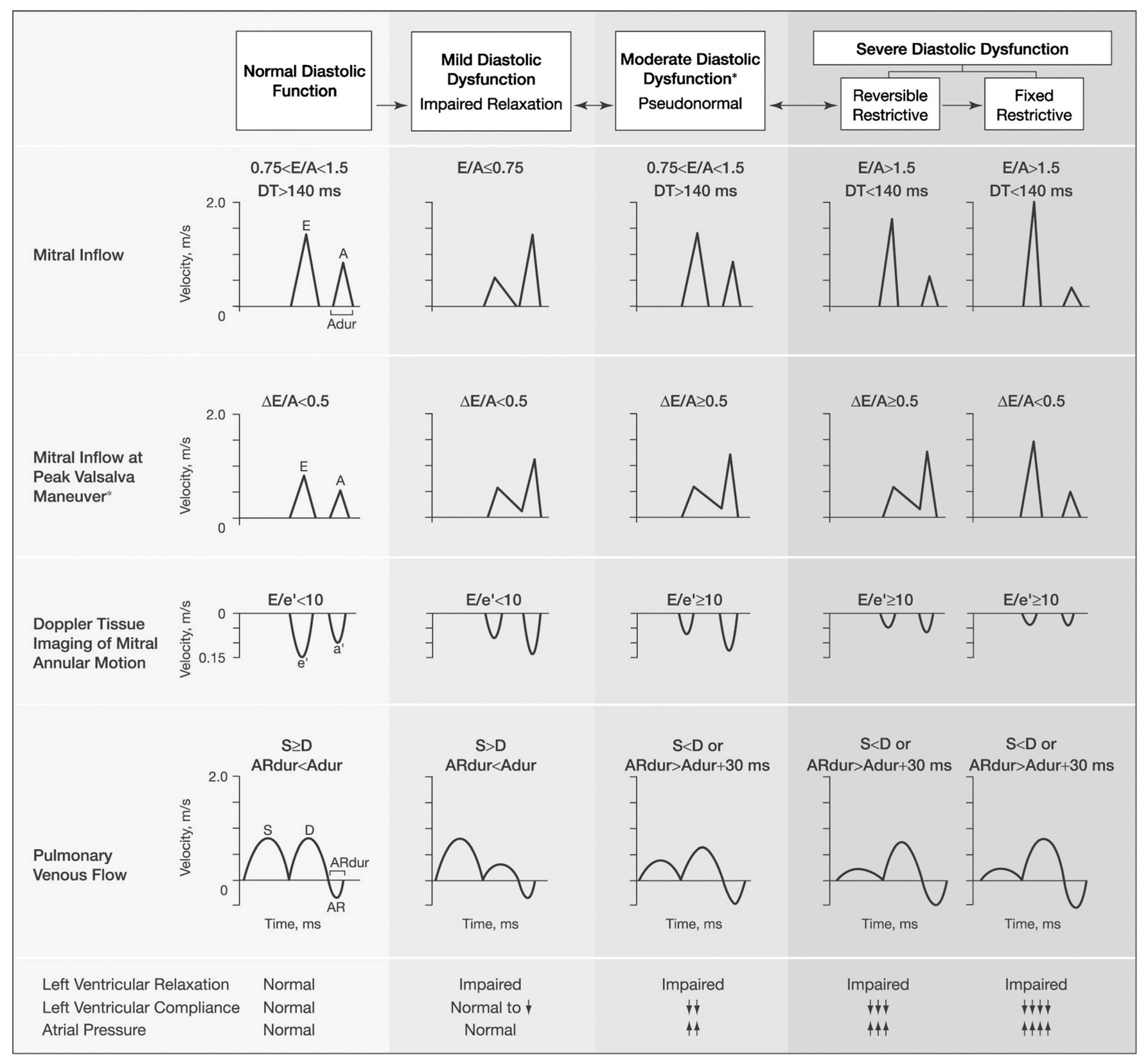

Fig. 1.

Doppler criteria for classification of diastolic function: reproduced with permission from [105]. $E$, peak early filling velocity; $A$, velocity at atrial contraction; $D T$, deceleration time; Adur, A duration; ARdur, AR duration; $S$, systolic forward flow; $D$, diastolic forward flow; $A R$, pulmonary venous atrial reversal flow; $e^{\prime}$, velocity of mitral annulus early diastolic motion; $a^{\prime}$, velocity of mitral annulus motion with atrial systole; $D T$, mitral $E$ velocity deceleration time 

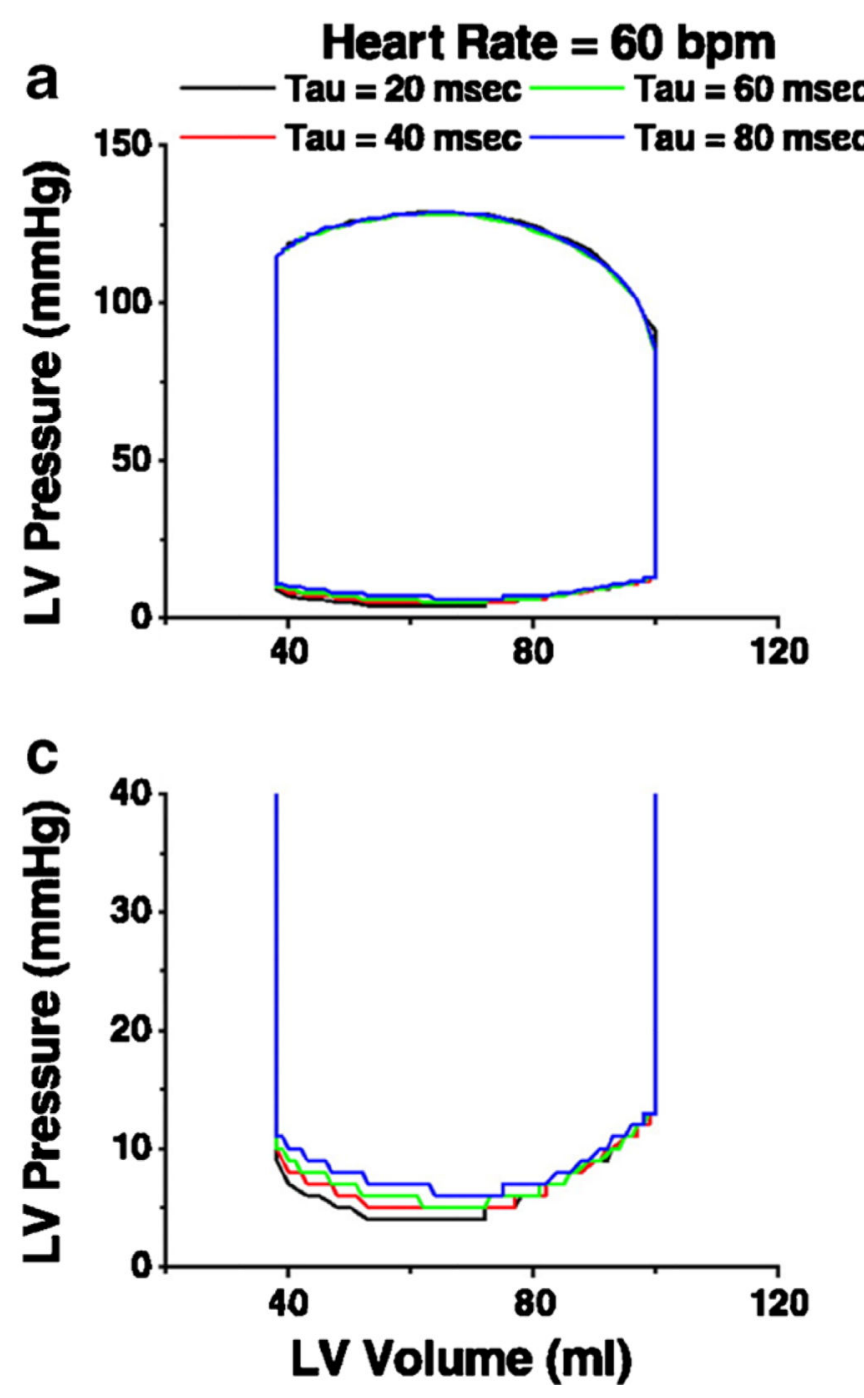

b

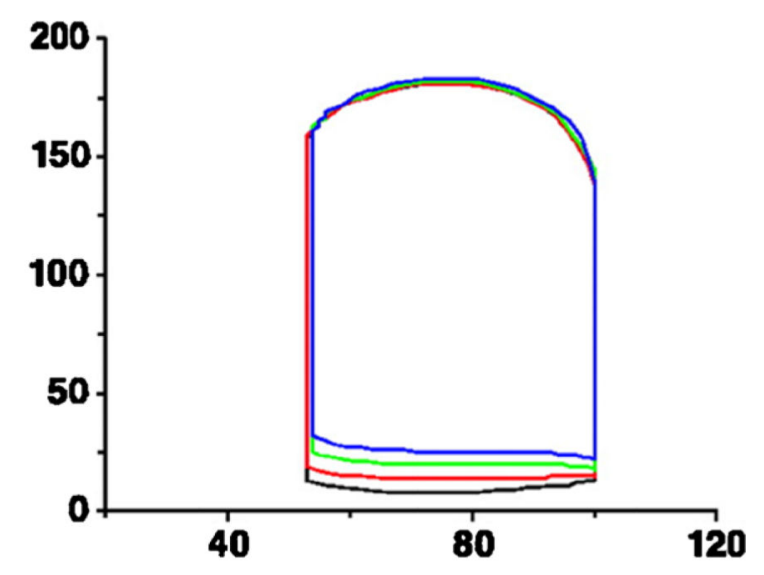

\section{Heart Rate $=120 \mathrm{bpm}$}

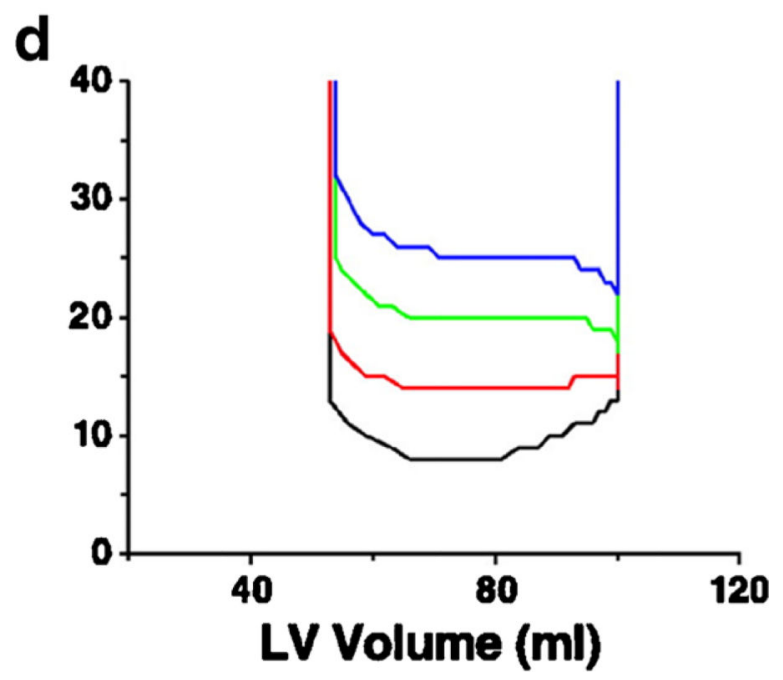

Fig. 2.

Impaired LV relaxation increases diastolic filling pressure in the presence of tachycardia: reproduced with permission from [50]. Modeling experiments defining the impact of variation in the time constant of isovolumic relaxation on pressure-volume loops at heart rate of $60 \mathrm{bpm}$ (a and c). Increases in $\tau$ values from 20 to $80 \mathrm{~ms}$ cause little change in the mean and end-diastolic LV pressure. At a heart rate of $120 \mathrm{bpm}$ (b and d), increases in $\tau$ values cause increases in the mean and end-diastolic LV pressure 

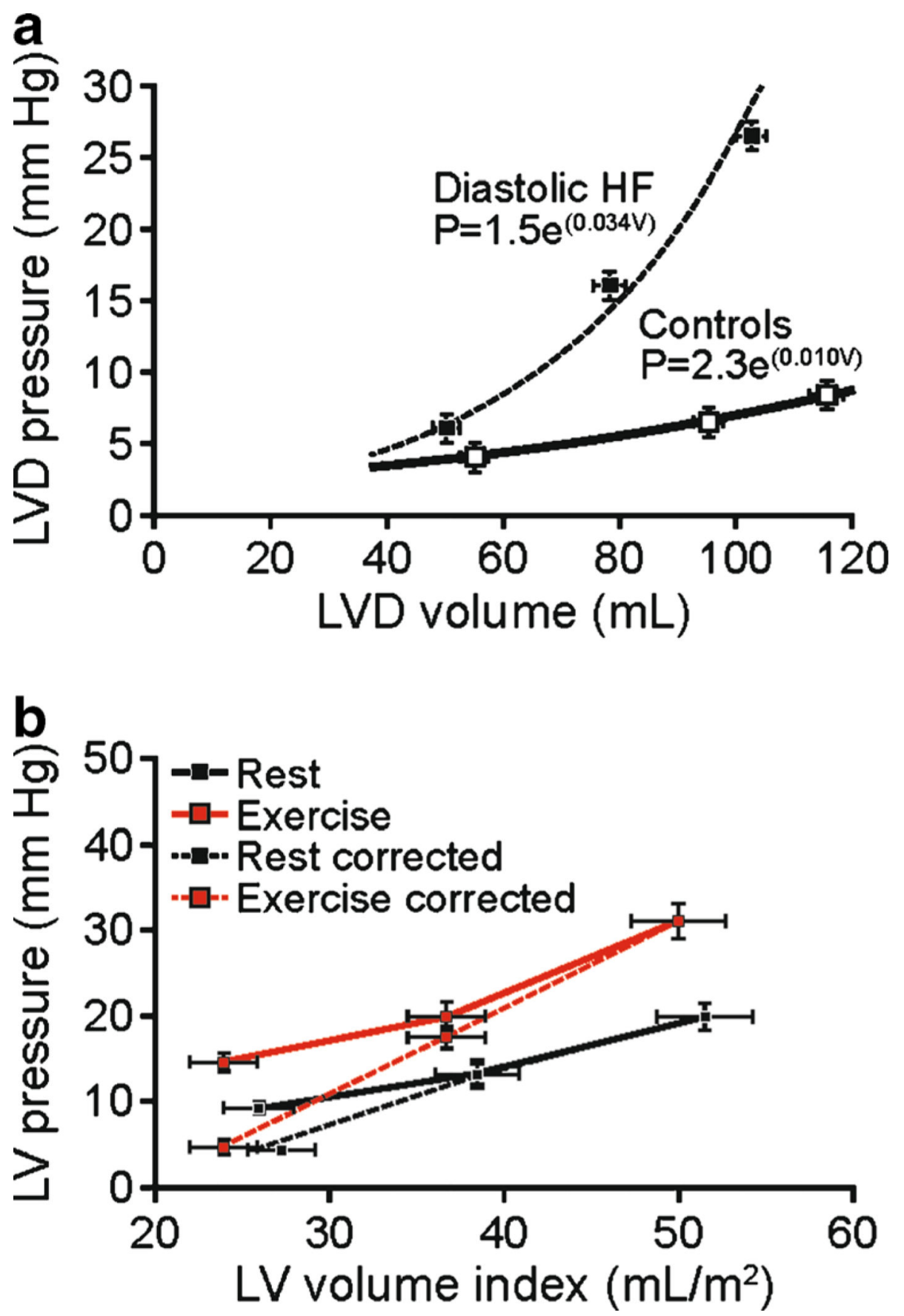

Fig. 3.

Increased left ventricular diastolic stiffness in HFpEF demonstrated by invasive measurement of the diastolic pressure-volume relationships. Panel (a) from Zile et al. (reproduced with permission from [135]) shows a significant increase in the passive stiffness of the left ventricle in patients with diastolic heart failure (HFpEF) as compared to controls. Panel (b) from Borlaug et al. (reproduced with permission from [14]) shows summary data for diastolic pressure-volume relationships of HFpEF patients at rest (black) and with exercise (red) plotting raw (solid) and relaxation-corrected (dashed) data. With exercise, the 
position of the diastolic pressure-volume relationship shifts upward with increasing diastolic pressure at similar volumes. The diastolic stiffness constants calculated from these relationships increased significantly with exercise 


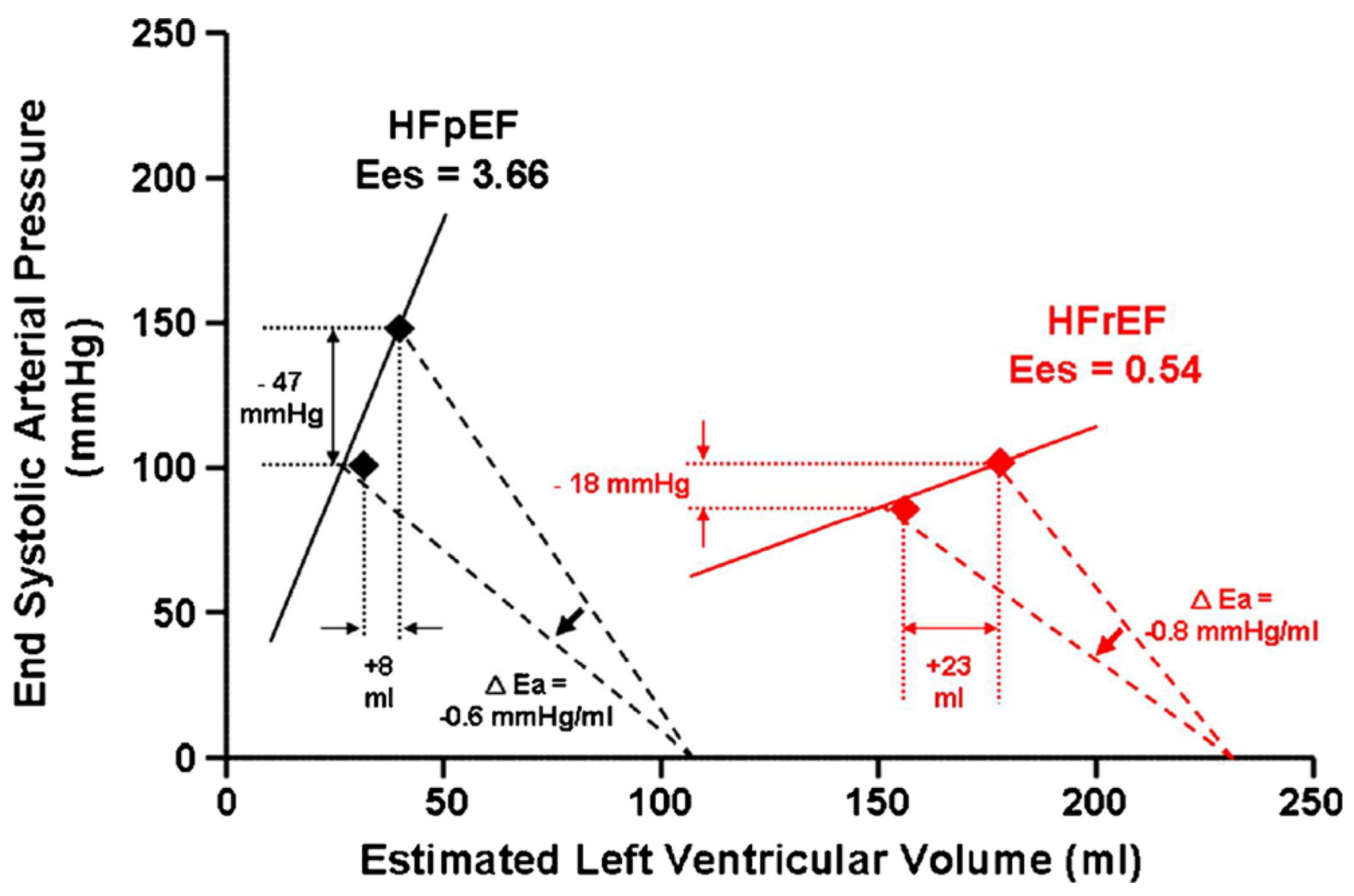

Fig. 4.

Differences in LV mechanics drive differential response to therapy in HFpEF and HFrEF: reproduced with permission from [112]. Observed and predicted end-systolic pressure volume changes with acute vasodilation in HFpEF and HFrEF. Patients were administered similar doses of nitroprusside with invasive hemodynamic monitoring. Observed changes in the end-systolic pressure-volume coordinates (diamonds) in HFpEF (black) compared to $\mathrm{HFrEF}$ ( $r e d)$ with reduction in arterial elastance $\left(E_{\mathrm{a}}\right.$, dashed lines) were similar to those predicted based on resting left ventricular end-systolic elastance ( $E_{\mathrm{es}}$, solid lines) and the observed changes in $E_{\mathrm{a}}$ with nitroprusside. Reduction in afterload produces greater blood pressure drop and less increment in stroke volume in HFpEF than HFrEF due to the difference in $E_{\mathrm{es}}$ 


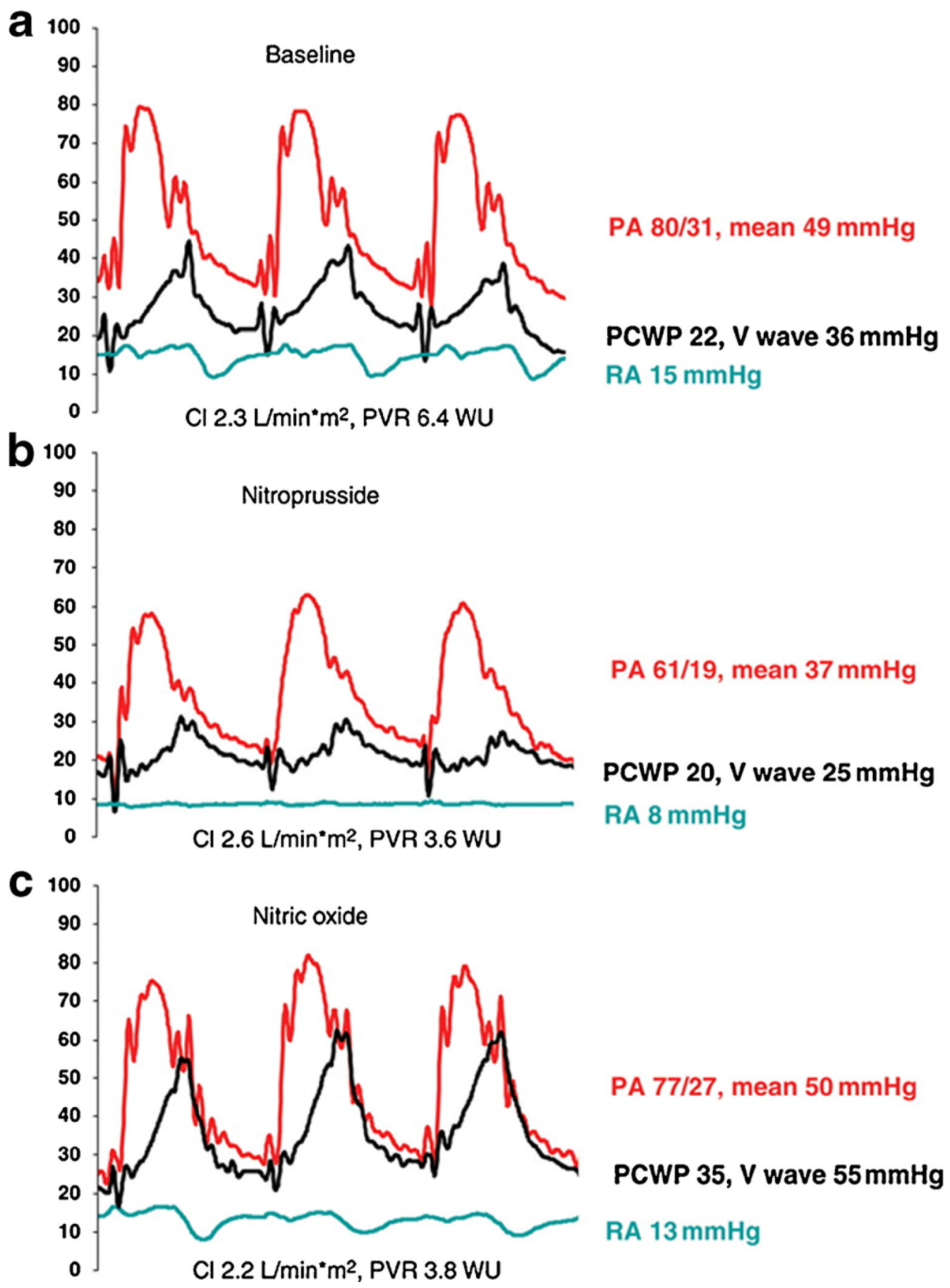

Fig. 5.

Reduced left atrial compliance resulting in giant atrial "v" waves in HFpEF: reproduced with permission from [8]. Hemodynamic tracings from a HFpEF patient are shown. a Severe pulmonary arterial hypertension is noted at baseline. There is also elevation in the pulmonary capillary wedge pressure with a prominent $\mathrm{V}$ wave $(36 \mathrm{mmHg})$. Right atrial pressure is elevated. b Sodium nitroprusside is administered, reducing pulmonary artery and pulmonary capillary wedge pressure and the $\mathrm{V}$ wave. $\mathbf{c}$ After re-equilibration, inhaled nitric oxide (iNO) is administered to increase pulmonary venous flow. Despite pulmonary arterial 
vasodilatation, pulmonary arterial pressures do not decline due to increased flow, but a marked rise in mean pulmonary capillary wedge pressure and in the V-wave amplitude is seen. Simultaneous echocardiography confirmed the absence of mitral regurgitation. Similar increases in $\mathrm{V}$-wave amplitude are seen with exercise in $\mathrm{HFpEF}$ and are a hemodynamic hallmark of HFpEF 


\section{Diastolic Dysfunction}

Resting Systemic and

Pulmonary Vascular

Dysfunction

DOE (NYHA II)

Impaired Vascular

Reserve

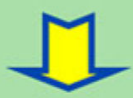

Subtle Resting

Contractile Dysfunction

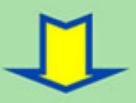

1
Impaired Systolic

Reserve

\section{Resting Symptoms}

\section{Impaired Ventricular- \\ Vascular Coupling}

Renal Dysfunction

NH Activation

RV Failure

Fig. 6.

Integrative HFpEF pathophysiology: patients with HFpEF have diastolic dysfunction. While arterial and LV systolic elastance (stiffness) are increased in HFpEF, resting contractile function is subtly impaired, as is the ability to appropriately dilate the peripheral vasculature and enhance chronotropic and LV systolic and diastolic performance with exercise (impaired reserve function). Chronic elevation of LV filling pressures leads to left atrial remodeling and dysfunction, mixed pulmonary hypertension, and, ultimately, right ventricular $(R V)$ remodeling and dysfunction. Atrial remodeling leads to atrial fibrillation (AF), which contributes prominently to HFpEF pathophysiology. The HF state leads to neurohumoral (NH) activation and aggravates underlying age- and comorbidity-related renal dysfunction. These perturbations express first as effort intolerance and progress to lead to advanced $\mathrm{HF}$ 


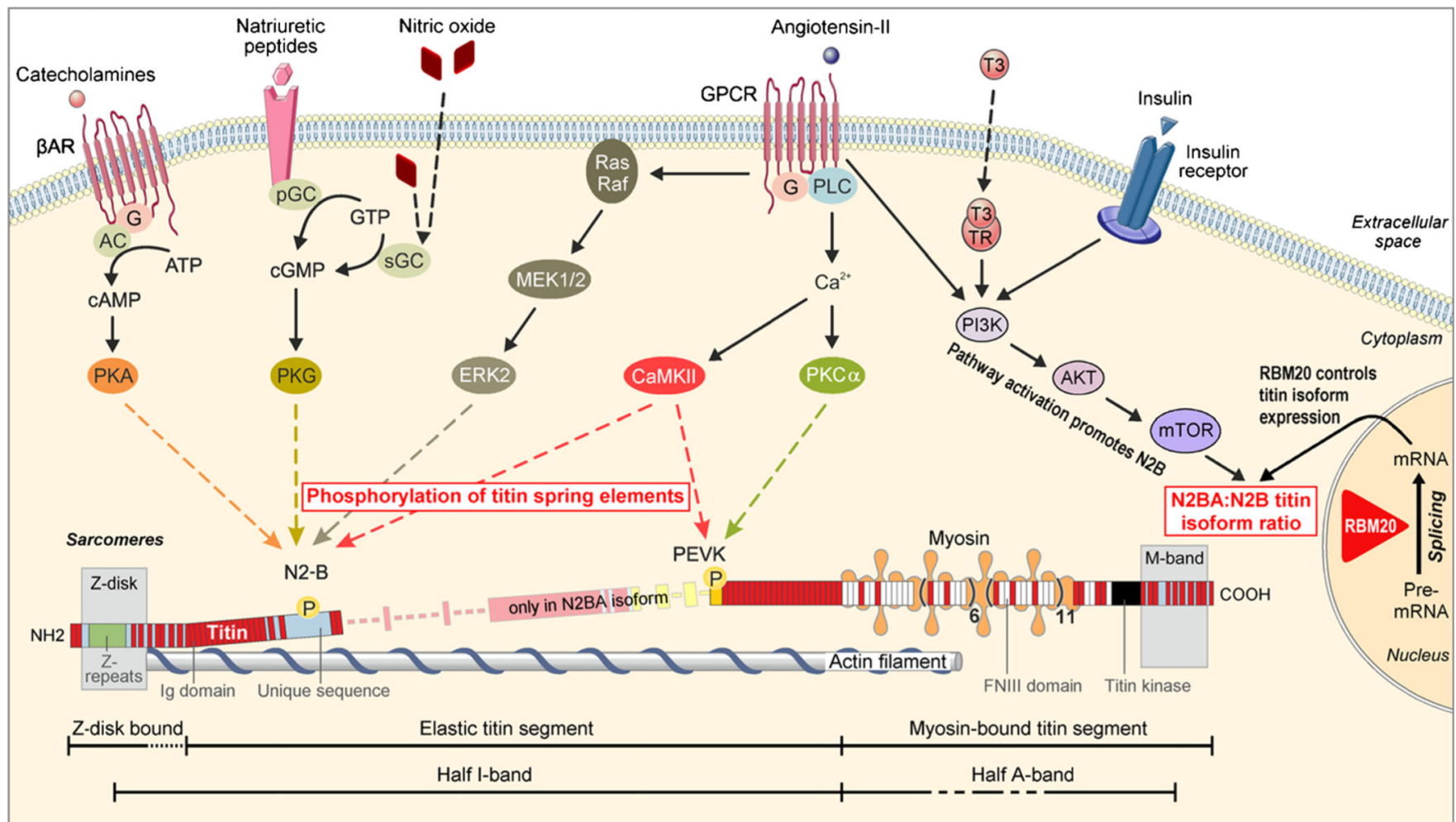

Fig. 7.

Cardiomyocyte signaling pathways involved in regulating cardiac titin stiffness.

Cardiomyocyte stiffness can be modulated by reversible phosphorylation $(P)$ either within the titin N2-B element by factors activating cAMP/PKA, cGMP/PKG, MEK1/ERK2, and CaMKIII or within the titin PEVK element by factors activating CaMKII and PKCa. Titin stiffness can also be modulated by altering the N2BA/N2B titin isoform expression ratio. $A C$ adenylyl cyclase, ATP adenosine triphosphate, $\beta A R \beta$-adrenergic receptor, $C a M K I I \mathrm{Ca}^{2+} /$ calmodulin-dependent protein kinase-II $\delta, c A M P$ cyclic adenosine monophosphate, $c G M P$ cyclic guanosinemonophosphate, ERK2 extracellular signal-regulated kinase-2, $G$ small Gprotein, GPCR G-protein-coupled receptor, GTP guanosine triphosphate, MEK1/2 MAPK/ERK kinase-1 and kinase-2, $m T O R$ mammalian target of rapamycin, $p G C$ particulate guanylyl cyclase, $P I 3 K$ phosphatidylinositol-3-kinase, $P K A$ protein kinase-A, $P K C$ a protein kinase-Ca, $P K G$ cGMP-dependent protein kinase-G, $P L C$ phospholipase-C, Raf rat fibrosarcoma protein, Ras rat sarcoma protein, $R B M 20$ RNA-binding motif protein-20, $s G C$ soluble guanylyl cyclase, $T 3$ triiodo-L-thyronine, $T R$ thyroid hormone receptor. Titin segments: Ig, immunoglobulin-like domain; N2-B, cardiac-specific I-band element; PEVK, disordered sequence (>70 \% P, E, V, and K residues); FNIII, fibronectin type III-like domain 
a

\section{AS HFREF HFNEF}

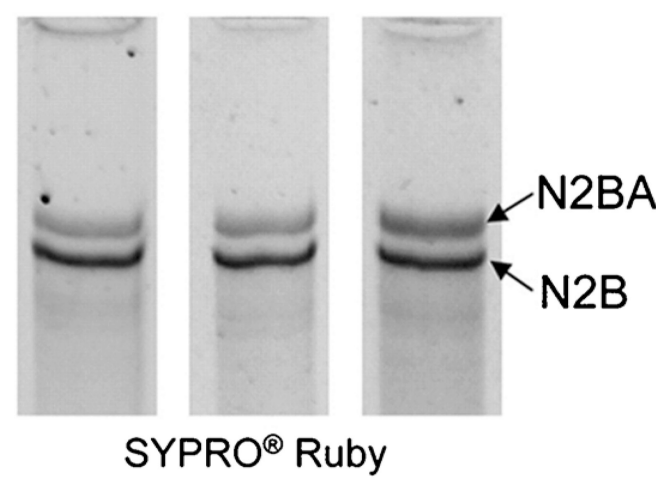

b
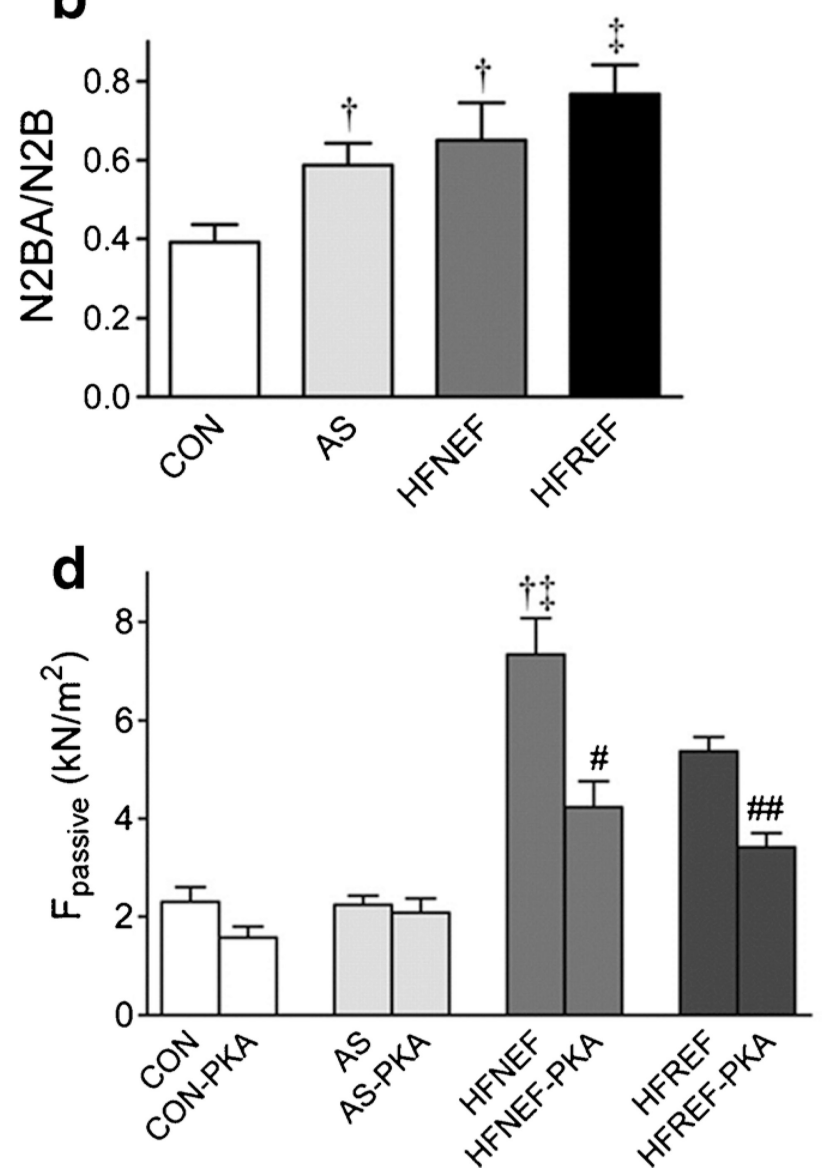

AS HFREF HFNEF

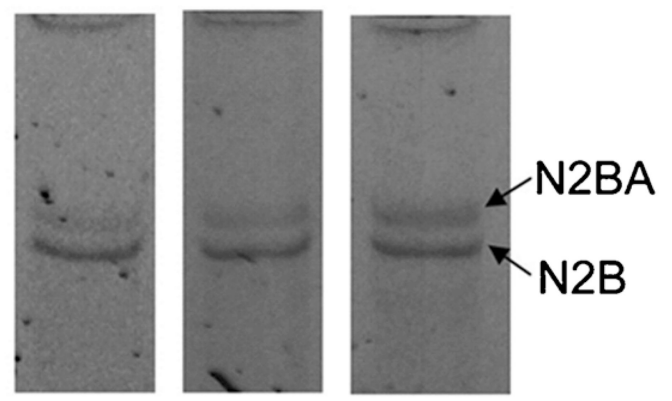

Pro- $\mathrm{Q}^{\circledR}$ Diamond
C

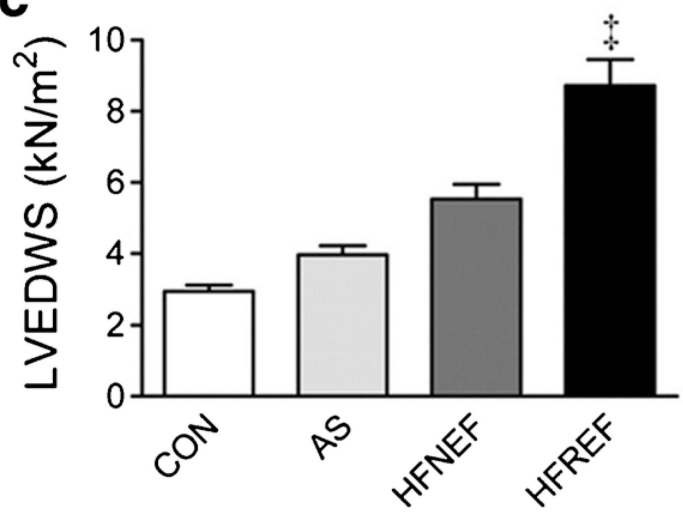

e

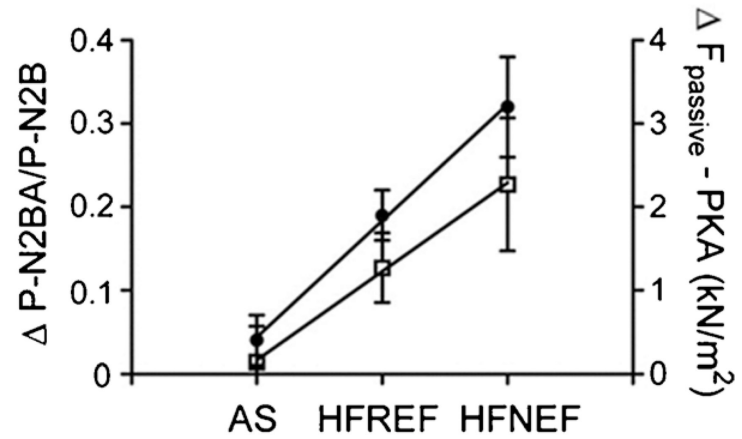

Fig. 8.

Titin isoform expression, titin isoform phosphorylation, and cardiomyocyte $F_{\text {passive }}$ in aortic stenosis $(A S), \mathrm{HFpEF}(H F N E F)$, and HFrEF patients: reproduced with permission from [10]. a Representative sequential gel electrophoresis with SYPRO Ruby and ProQ Diamond phosphoprotein stain in left ventricular samples from patients with AS, HFrEF, and HFpEF showing phosphorylation of titin isoforms. b Higher N2BA/N2B ratio in AS, HFpEF, and HFrEF patients than in the control $(C O N)$ group ( $\dagger P<0.05$ vs. $C O N ; \ddagger P<0.001$ vs. $C O N)$. c Higher left ventricular end-diastolic wall stress ( $L V E D W S)$ in HFrEF patients than in CON, 
AS, and HFpEF groups $(\$ P<0.001$ vs. CON, AS, or HFpEF). d Higher cardiomyocyte stiffness $\left(F_{\text {passive }}\right)$ in HFpEF patients than in CON, AS, and HFrEF patients $(\ddagger P<0.001$ vs. CON or AS; $† P<0.01$ vs. HFREF). After in vitro administration of PKA, $F_{\text {passive }}$ fell in HFpEF ( $\# P=0.0001$ vs. HFNEF) and HFrEF cardiomyocytes (\#\#P=0.0001 vs. HFREF). e Parallel trends in AS, HFREF, and HFNEF patients of the N2B phosphorylation deficit ( $\mathrm{P}$ N2BA/P-N2B, open squares) and the PKA-induced fall in $F_{\text {passive }}$ (filled circles) 


\section{Myocardial Remodeling in HFPEF Importance of Comorbidities}

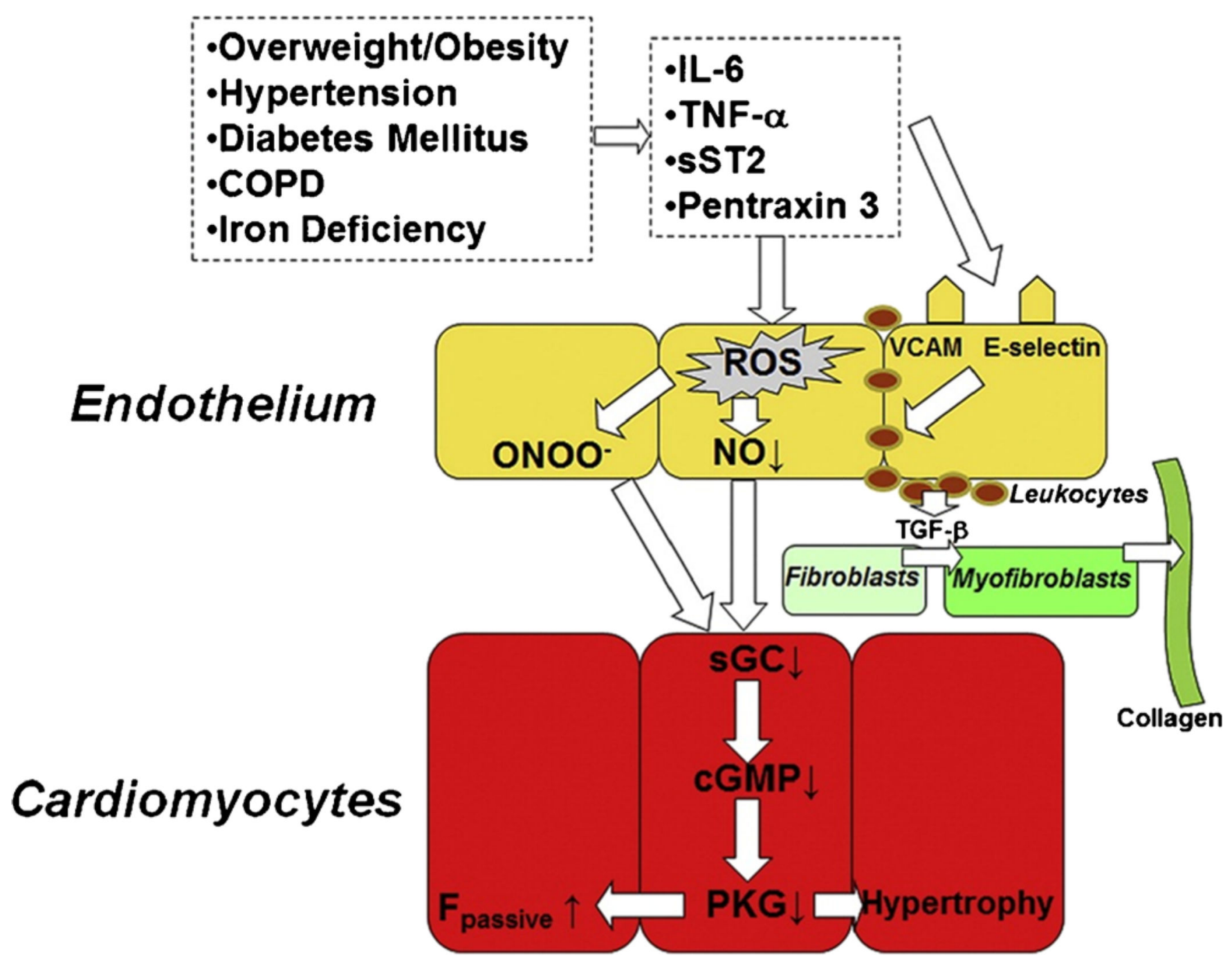

Fig. 9.

Novel unifying paradigm for HFpEF pathophysiology: reproduced with permission from [96] 